\title{
Science as a Self-Organizing Meta-Information System Christian Fuchs
}

\author{
Institute of Design and Technology Assessment \\ Vienna University of Technology \\ Favoritenstr. 9-11/187 \\ A-1040 Vienna \\ Austria \\ christian@igw.tuwien.ac.at \\ $++43 / 1 / 58801-18733$
}

Acknowledgement: This paper is based on research done within the framework of the project 'Human Strategies in Complexity: Philosophical Foundations for a Theory of Evolutionary Systems' (http://www.selforganization.org) funded by INTAS (\#0298) and supported by the Austrian Federal Ministry of Education, Science and Culture.

\begin{abstract}
Four basic problems that a theory of science has to deal with concern epistemology, structure, causality, and dynamics of science. These problems deal with the relationship of induction/deduction, actors/structures, internal/external factors, and continuity/discontinuity. Traditionally they have been solved one-sidedly. Considering science as a self-organizing system allows a more integrative approach.

Science is a complex, nonlinear system that is made up of two moments: scientific actors and scientific structures. Scientific self-organization operates synchronously and diachronically. Synchronous scientific selforganization is a mutual production process between scientific actors and structures. Scientific systems are selforganizing units that perform the production of theories and truths by the way of a productive, circular causal duality of scientific actors and scientific structures. Science is a dynamic system where research practices produce and reproduce structures that produce and reproduce research practices. Scientific structures are medium and outcome of scientific actions. At the action level one can find a systemic hierarchy that is made up of individual researchers, research groups, scientific communities, and the overall scientific community. Scientific structures include theories, research institutions, technologies, journals, publications, science funds; norms, values, and rules of scientific conduct. The main scientific practices can be categorized as genuinely scientific practices (innovation, dissemination, scientific interchange, funding-related activities, teaching), cultural practices (public discourse), political practices (science policy), and economic practices (action related to scientific knowledge as commodities, patents, science-industry-partnerships, sponsorship).

Science is an open system that is structurally coupled to other subsystems of society, it is neither internally, nor externally determined, its development is caused by a complex interplay of internal and external factors, it is a relatively autonomous system. Systems in nature and society act as a sort of data for the scientific system, research processes establish an informational relationship between the scientific system and its environment in the sense that theories are complex, non-linear reflections of environmental processes. Due to the fact that all complex systems are informational, one can say that science produces information about information systems. Science is a $2^{\text {nd }}$ order information system, it produces meta-information. Philosophy of science is a science of science, it produces information about information about information, it is a $3^{\text {rd }}$ order information system. The metaphor of science as a grand hypertext refers to the self-referential character of scientific texts. A scientific text by the way of citation refers to other scientific texts, it incorporates part of the history of science, and methodologically discusses other texts.

The formation of scientific knowledge can be described as a double-process of induction and deduction, abstraction and concretization, where scientific knowledge consists of both empirical knowledge and theoretical knowledge and is formed in loop that consists of two self-organization processes. The self-organization of scientific knowledge is a mutually productive relationship between experience and theory. Scientific knowledge is a unity of experience and theory. The self-organization of scientific knowledge is a dialectical cycle where signals from material reality are transformed into experienced data that is interpreted and results in hypotheses and theories which are transformed into methods and technologies that are employed in order to cause effects in material reality that can again be observed as data. In this self-organization process there is the bottom-upemergence of theoretical knowledge and the top-down-emergence of experiences and material effects.

Each scientific theory is a truth claim, but one that is based on a systematic methodology, permanent evaluation and correction, and conflict-based discourse. Hence scientific truths are not absolute truths, they are truths-inquestion, truths-in-discourse, and truths-in-conflict, and truths-in-development. One can distinguish formal, adequate, discursive, and practical truth of a theory. Due to the fact that the knowledge-based society is a high risk society, practical truth of science in the form of an ethically responsible science is of central importance.
\end{abstract}


Diachronic self-organization of science means that dominant scientific paradigms at some point of time loose their effectiveness, paradoxes and instabilities show up, science enters crisis, a new dominant paradigm emerges. If a large gap between scientific theory and the problems posed for science by itself and by society emerges, the dominant structural patterns are increasingly questioned. This can have scientific or wider societal causes, or a combination of both. The resulting crisis is a process of creation and destruction. The whole process is one of the emergence of scientific order from noise. Variation is a permanent phenomenon of scientific evolution, but in phases of instability where the self-organization of science shifts from self-reproduction to order from noise the degree of variation and development by chance is much larger.

Keywords: science, research, system, self-organization, knowledge, information

\section{Introduction}

The aim of this paper is to discuss some foundations of considering science as a selforganizing system. The main question is whether it is possible to apply aspects of selforganization such as self-reproduction, emergence, instabilities, fluctuations, order from noise, self-referentiality, circular causality, synergism, complexity, nonlinearity, information production, bifurcation points to science as a system.

In section one I give an introduction to the fundamental issues at hand and the scientific state concerning the relationship of self-organization and science. My own approach is based on general concepts of social self-organization and knowledge as a social process. In order to be able to point out that science is a self-organizing knowledge system, I will give an introduction to some foundations of a theory of social self-organization in part two. Scientific self-organization operates on a synchronous (section 3) and a diachronic level (section 4). On the synchronous level I will first identify basic scientific structures and actors (3.1.), then I will analyze the informational level of synchronous scientific self-organization (3.2.). On the diachronic level the process of the emergence of scientific order from noise in bifurcation points/phases of instability will be analyzed.

A theory of science faces at least four basic problems that it has to deal with. One is an epistemological one, the other ontological ones. These problems concern epistemology, structure, causality, and dynamics of science and can be solved in different ways, depending on which methodological approach one chooses. The epistemological problem focuses on how the relationship of experience and theory should be conceived. Inductivists argue that all scientific knowledge can be induced from empirical experiences, this is a subjectivistic position. Deductivists argue that experimental testing can only be deduced from objective scientific knowledge. Inductivism doesn't take into account that all empirical knowledge is based on theoretical premises, deductivism doesn't take into account that theory as an abstraction of reality is grounded in the sensual experience of this reality. Dialectical approaches argue that scientific knowledge is a process that is constituted in a mutual connection of induction and deduction. The structure problem deals with the question whether scientific development is determined by human practices or by structures. Action-based accounts of science argue that scientific development is due to intersubjective actions, structuralistic theories argue that it is due to objective structures. An example for the first kind of theory is Thomas Kuhn's (1962) theory of science which argues that science develops due to intersubjective consensus and dissent, an example for the second kind is the classical functionalistic sociology of science in the tradition of Robert Merton (1996) who argues that science is an institutionalization of objective values. Action theory doesn't take into account that action is conditioned and limited by objective factors, structuralism doesn't take into account that human beings are creative and hence change structures. A dialectical approach explains science as a system where actions and structures produce each other mutually, it tries to bridge the dualism between actors and structures. The causality problems deals with the 
question how scientific development is caused. Internalistic approaches argue that science is itself a autonomous subject with laws of development that are independent of external factors. Such theories are e.g. put forward by Kuhn (1962) and Luhmann (1990). Externalistic theories argue that scientific development is determined by factors that are external to science, such as the economy. Such accounts can e.g. be found in traditional Marxist theories. Dialectical approaches try to bridge the gap between internalism and externalism by arguing that scientific development is caused by a complex interplay of internal and external factors. The problem of dynamics deals with the question how change in science happens. Synchronous accounts argue that science evolves slowly, continuously, and in a cumulative way. An example are traditional cumulative accounts of science such as the one of Derek De Solla Price (1963). Diachronic accounts explain scientific development as a process where spontaneous revolutionary discontinuous breaks cause the end of old paradigms and the appearance of new ones. The most famous diachronic theory of science has been worked out by Thomas Kuhn (1962). Purely synchronous theories can't explain fundamental scientific change (scientific revolutions), purely diachronic theories are blind for permanent change on lower levels of science. A dialectical approach explains scientific development as a process where novelty emerges continuously in phases of stability, but where phases of stability are followed by phases of instability in which fundamental novelty that sublates old knowledge emerges.

\begin{tabular}{|l|l|l|l|l|}
\hline & $\begin{array}{l}\text { epistemology: } \\
\text { induction vs. } \\
\text { deduction }\end{array}$ & $\begin{array}{l}\text { structure: } \\
\text { actors vs. } \\
\text { structures }\end{array}$ & $\begin{array}{l}\text { causality: } \\
\text { internal vs. } \\
\text { external }\end{array}$ & $\begin{array}{l}\text { dynamics: } \\
\text { continuity vs. } \\
\text { discontinuity }\end{array}$ \\
\hline subjectivism & Inductivism & Action Theory & Internalism & Synchronism \\
\hline objectivism & Deductivism & Structuralism & Externalism & Diachronism \\
\hline $\begin{array}{l}\text { subject- } \\
\text { object- } \\
\text { dialectic }\end{array}$ & $\begin{array}{l}\text { Unity of Induction } \\
\text { and Deduction }\end{array}$ & $\begin{array}{l}\text { Unity of Action } \\
\text { and Structure }\end{array}$ & $\begin{array}{l}\text { Unity of Internal } \\
\text { and External } \\
\text { Causes }\end{array}$ & $\begin{array}{l}\text { Unity of } \\
\text { Continuity and } \\
\text { Discontinuity }\end{array}$ \\
\hline
\end{tabular}

Tab. 1: Different approaches for solving the four basic problems of a theory of science

Modern society has transformed itself into a flexible fluid where all subsystems are networked and interconnected, new information- and communication technologies (ICT) allow communication across large spatial and temporal distances, action functions at a global distance, modernization risks have become a permanent reality, and organizations have an increasingly flexible and decentralized character. Science and technology are important media of these transformations and are themselves confronted with changes of the way they function. In order to explain the role of science and technology in the globalizing information society, a concept of science seems to be necessary that can explain the dynamic and networked character of society, science, and technology. Self-organization theories seem to be particularly suited as a methodological foundation for a theory of science because they have a strong emphasis on networking, flexibility, dynamics, complexity, non-linearity, multidimensionality, ambiguity, and uncertainty.

I will now give an introduction to the most important approaches that have considered science as a self-organizing system and will try to show how they have solved basic problems of a theory of science.

Niklas Luhmann (1990) argues that knowledge is not an aspect of and can't be assigned to a human subject, but that it is an attribute of communication, a component of an autopoietic operation. There would be no individual conscious knowledge, knowledge couldn't be stored in the brain, it wouldn't be something that one can have or keep. Knowledge would be a 
condensation of observation (Luhmann 1990: 123), cognitive stylized meaning (138).

Communication would permanently actualize knowledge. Knowledge would be the sediment of communication, it would mark cognitive expectations (139). Knowledge would try to steer observations of others by setting expectations and experiences (146) ${ }^{1}$ and would always be connected to a structural coupling of systems that produces reactions to irritations in a system (165).

Science would be a communication system that observes and describes. It would work out categories in order to decide if certain statements are true or not (124) and would be a functionally differentiated subsystem of society that assesses the truth of knowledge, it would maintain and innovate knowledge $(166,217,355,617)$. Truth would mean that knowledge is tested and evaluated (167), whereas falseness would mean error (202). It would be a binary coded medium, a symbolic generalized communication medium that increases the possibility that certain communications are accepted. Truth for Luhmann means a form that produces the difference true/false. It would be internally produced by the scientific system and relative to the system, there would be no external truths (198), truth would be non-teleological (285). Science would be autopoietic in the sense that in it communications permanently produce new communications, these communications would be oriented on the binary code true/false. Science would be a system of second order observation, it would observe observation. The observing of observation that is oriented on the binary code true/false would be a communication belonging to the scientific system (174). Scientific observation could only function with the help of theory (193). For Luhmann science is a self-organizing or autopoietic system because it would permanently produce communications that decide whether knowledge is true or false $\mathrm{e}^{2}$. The communication of truth would be the elementary unit of the autopoietic system science (284). Science would not increase certainty, but uncertainty (325). Science would be structurally coupled to other systems like the economy and polity, but it would be an operationally closed, internally structurally determined, autonomous system that decides all by itself what is true and what is false (292f, 299, 704).

Luhmann conceives social self-organization as a self-referential mechanism where communication produces communication. Hence science is conceived as a specific selforganizing system that uses the binary code true/false for maintaining its autopoiesis. The main problem with this approach is that it is a type of structural functionalism that doesn't take into account the importance of knowledgeable, creative, active human beings in society (cf. Fuchs 2002a, 2003c). If one wants to consider a social system as autopoietic or selfreferential, the permanent (re)production of the elements by the system is a necessary condition. Luhmann argues that individual human beings are not permanently produced, hence the elements of a social system would have to be communications. In Luhmann's theory, communication in a social system is both element and structure, there is no duality of structure and action, only communication as a self-referential monad. But a communication is

\footnotetext{
1 „Etwas war als ,Wissen’ mitgeteilt - das heisst: es soll(!) so beobachtet werden, als ob die Beobachtung unter diesen Prämissen stattgefunden hätte“ (Luhmann 1990: 146f).

${ }^{2}$,Wissenschaft ist demnach ein strukturdeterminiertes System eines besonderen Typs. Aber ist sie darüber hinaus auch ein autopoietisches System, das heißt: ein System, das die Elemente, aus denen es besteht, durch das Netzwerk der Elemente, aus denen es besteht, selbst produziert? Man kann diese Frage bejahen, wenn man als Element die wissenschaftliche Kommunikation ansieht, die Wahrheit unter Ausschluß von Unwahrheit (bzw. umgekehrt Unwahrheit unter Ausschluß von Wahrheit) behauptet. Sobald die Symbolik des Mediums Wahrheit innerhalb der allgemeinen gesellschaftlichen Kommunikation eine besondere Qualität generiert, die nur in rekursivem Anschluß an frühere und an in Aussicht stehende weitere Kommunikationen desselben Systems gewonnen werden kann, entsteht ein autopoietisches System, das eben diese Elemente durch eben diese Elemente erzeugt und sich dadurch von einer Umwelt anderer Kommunikationen abgrenzt" (Luhmann 1990: 282f).
} 
not a subject, a communication doesn't produce communications, only human beings produce communications that cause reactions and the further production of communications by other human beings. Hence the assumption of a duality between structure and action seems to be a necessary condition for adequately describing self-referential, circular causal, reflexive processes in a social system.

Also concerning science as a system, the same shortcomings can be found in Luhmann's theory. Science is not a system where communicative truth produces communicative truths because only human actors can scientifically communicate and decide individually and collectively what should be considered as true and false. So what is missing is the assumption that scientific structures are both medium and outcome of scientific actions by individual and collective scientific actors. As an alternative I suggest to argue that social self-organization should be viewed as the mutual production of actors and structures, social structures produce man as a social being just like man produces social structures as a necessary condition for his/her social being, the human being is creator and created result of society. As I will try to show this idea can also be applied to science as a system.

Luhmann's theory of science is structuralistic (structure problem), internalistic (causality problem), and synchronous (problem of dynamics). It is a one-sided theory that can't explain the important of human actors in science, external influences, and diachronic change.

Krohn and Küppers (1990) argue that there is a difference between science and research: "Research is the production of knowledge, science is concerned with the creation of conditions favorable to the continuation of research". I don't think that such a dualism makes much sense because one can distinguish different practices of scientists, but both activities that Krohn and Küppers mention take place in one and the same system. Hence I suggest that science is a system of organized and systematic knowledge production, whereas research is the basic practice of human actors in this system and can be subdivided into different research practices. Science is a systemic term, research is a term that focuses on processes and practices within the scientific system.

Other than Luhmann, Krohn and Küppers $(1989,1990)$ give attention to the importance of human actors in scientific self-organization and stress the importance of research groups as actors. They distinguish three different types of activities of such groups: integrative activities (self-maintenance of the group by constituting beliefs, attitudes and intention), research activities (production of knowledge), and scientific activities (marketing of research results, acquiring new research tasks). Research would be possible as recursive interactions between researchers in a research group, each researcher would produce information as an output that functions as informational input for other researchers in his group (1989: 28ff). The selforganization of research is considered as a recursive process between theory and method, i.e. theoretical and observational activities, that produces new knowledge (Krohn/Küppers 1989: 46-65, 1990: 213f). The observational part is itself considered as a recursive loop that connects experimental design (construction) and the observation of effects (data) based on the binary code successful/failure. The theoretical part is considered as a recursive loop that connects the derivation of expectation (hypotheses) with the interpretation of data (information) based on the binary code true/false. Theory would be connected to method by the process of operationalization, method to theory by the process of explanation.

Science (Wissenschaft) would be the environment of research, it would have scientific, nonscientific, and hybrid aspects (1989: 66ff). Krohn and Küppers (1989: 66-121, 1990: 215ff) argue that there are six environments of research that together form the scientific system 
(laboratories/scientific community, journals, science policy and research planning, teaching, fields of practice such as industry, health system, education, juridical system, the public). In the last chapter of Krohn/Küppers (1989: 122ff), what has prior been called science is now termed scientific institutions and the scientific system is conceived as a hypercycle, i.e. a cyclical connection of research groups and scientific institutions. Each of the two systems would organize itself, but they would be connected by receiving inputs from each other and generating outputs for each other. The research groups would produce knowledge as inputs for the institutions, the institutions would construct scientific networks as inputs for the research groups.

The advantage of this approach is that it tries to connect the self-organization of science/research to human actors. The problem is that the dualism between science and research lacks a unifying concept of social self-organization that shows how both realms of activities are connected. The distinction of science and research can only be made analytically, but both activities are carried out by the same actors in the same system. A dualistic approach is not able to show that in both realms to a certain extent the same structures and actors are present. Hence it is better to describe science as a system, and research as a plurality of different types of practices that are connected to scientific structures, and to assume that scientific practices and structures together form the central moments of scientific systems. The formation of new knowledge in the model of Krohn and Küpper is the area of activity of research, whereas science (Wissenschaft) organizes the infrastructure of research. Terminologically this doesn't make much sense because the term Wissenschaft means to create knowledge, the term science stems from the Latin scientia which means knowledge. But if the nature of Wissenschaft is not conceived as the direct creation of knowledge as in the case of this model, then the term doesn't make any sense. This imprecise usage of terms is further complicated by the fact that science is first considered as the totality of the environments of research, but is then conceived as a hypercycle of research groups and scientific institutions. In order to avoid such shortcomings we suggest that it is better to conceive research groups and scientific communities at an actor level, and all institutions, rules, and resources of science at the structural level, and to understand scientific systems as the mutual connected unity of actors and structures. Hence not each level is self-organizing as Krohn and Küppers argue -, but self-organization is the mutual production process between scientific actors and structures. Such an approach can be employed at different systemic levels: the individual researcher, the research group, scientific communities, and science as a totality. The main difference between my approach and the one of Krohn and Küppers is that they consider research and scientific institutions as two separately selforganizing systems (that are coupled in a hypercycle), whereas I argue that such a differentiation creates terminological and theoretical problems and hence one should see scientific systems as self-organizing units that perform the production of theories and truths by the way of a productive, circular causal duality of scientific actors and scientific structures.

The approach of Krohn and Küppers is dialectical (concerning epistemology), action-based (structure problem), internalistic (causality problem), and synchronous (problem of dynamics).

Rudolf Stichweh (1990) makes a distinction between social self-organization and social autopoiesis. The first would integrate as many elements from the outside as possible, the second would have a more closed character and would exclude certain intruding elements in order to maintain itself. European science from the $16^{\text {th }}$ to the second half of the $18^{\text {th }}$ century would have been self-organizing because its main function would have been the conservation, organization, and imitation of older scientific knowledge. Since the $19^{\text {th }}$ century European 
science would have been autopoietic, focusing on internal knowledge innovation and selfreflection. Stichweh's arguments are based on Luhmann's view that in science communicative truth produces communicative truths. There surely are different types of closure of self-organizing systems, but self-organization is a more general concept than autopoiesis, autopoietic systems are one type of self-organizing systems. It is questionable that the term autopoiesis should be used in sociology because it blurs the difference between biological and social self-organization. Older theories are not externalities of the scientific system, they are internalities and belong to the structural aspects of the system. Hence European science in the $17^{\text {th }}$ and $18^{\text {th }}$ century was mainly based on an internal logic, if old theories were external to science they would have to belong to another subsystem of society such as polity or economy. Like Luhmann's account of science, Stichweh's theory of science is structuralistic, internalistic, and synchronous.

A very interesting, but long-forgotten and hardly acknowledged, materialistic discussion of the self-organization of science has been put forward by Günter Kröber (1988). He argues that science is an irreversible self-organization process. Scientists that have a lot of resonance in the sense that they have comparable scientific knowledge would be able to jointly produce new cognitive structures, i.e. new scientific ideas. The emergence of new qualities in a selforganizing system would be due to the synergetic co-operation of entities. In science, human beings would communicate and co-operate in order to produce new cognitive structures. Irreversibility in science would mean that theories change dynamically: old ones are recombined, new ones emerge, old ones are modified or disappear, etc. New cognitive structures would emerge permanently in science. Scientific knowledge would have to be permanently reproduced in science and labour processes in order to continue its existence. If it exists only in the form of a set of characters in a book, it would only be potential knowledge, only if it is embedded into actual scientific labour and if it is condition of existence and development of new knowledge, would it be actual knowledge, a dissipative cognitive structure. The development of science would only be possible if new knowledge emerges permanently and old knowledge is permanently reproduced in science and education. Science would develop in the form of bifurcations where different evolutionary paths emerge from existing theories. The result would be a "tree of scientific knowledge" (Kröber 1988: 172). In each new period of scientific development, a stronger differentiation of actual and potential development paths would emerge. None of these paths would be reversible, none could be predicted with full reliability. Scientific bifurcations would be nonlinear in nature. Time and place of a scientific bifurcation would depend on external social and internal scientific factors, aspects of both scientific and social problems. Bifurcation points in science would be points of revolutionary transformation triggered by fluctuations and instabilities. Kröber's account of science is action-based (structure problem), externalistic (causality problem), diachronic (problem of dynamics).

This discussion shows that basic problems of a theory of science have thus far been solved rather one-sidedly by approaches that consider science as a self-organizing system, a dialectical theory of scientific self-organization is missing. This paper won't work out such a theory, but it will try to make a contribution for the foundations of such an approach. Selforganization theory puts forward a dialectical logic: Concepts from self-organisation theory such as control parameters, critical values, bifurcation points, phase transitions, non-linearity, selection, fluctuation and intensification in self-organisation theory correspond to the dialectical principle of transition from quantity to quality (Fuchs 2003h). What is called emergence of order, production of information or symmetry breaking in self-organisation theory corresponds to Hegel's notions of sublation (Aufhebung) and negation of the negation (ibid.). Self-organization puts forward dialectical relationships of subject/object, part/whole, 
chance/necessity, concrete/abstract, specific/general (ibid.). Hence trying to conceive the selforganization of science as a dialectically and solving the basic problems of a theory of science that concern epistemology, structure, causality, and dynamics dialectically makes sense. My approach tries to make a contribution to bridging the gap between induction/deduction, action/structure, internal/external, continuity/discontinuity in the theory of science. In order to do so I first have to outline some foundations of social self-organization.

\section{Foundations of Social Self-Organization}

Social analysis has to begin with individuals producing in a society, i.e. the existence of living human individuals. The active human being is the component or element of a social system. We term the self-organization of social systems "re-creation". Societal structures don't exist externally to, but only in and through human agency. By interaction of human actors, new social qualities and structures can emerge that cannot be reduced to the individual level. This is a process of bottom-up emergence that is called agency. Emergence in this context means the appearance of at least one new systemic quality that cannot be reduced to the elements of the system. So this quality is irreducible and it is also to a certain extent unpredictable, i.e. time, form and result of the process of emergence cannot be fully forecasted by taking a look at the elements and their interactions. Structures also influence individual actions and thinking. They constrain and enable actions. This is a process of top-down emergence where new individual and group properties can emerge. The whole cycle is the basic process of systemic societal self-organization that can also be called re-creation because by permanent processes of agency and constraining/enabling a system can maintain and reproduce itself (see fig. 1). It again and again creates its own unity and maintains itself. Societal structures enable and constrain actions as well as individuality and are a result of actions (which are a correlation of mutual individuality that results in sociality).

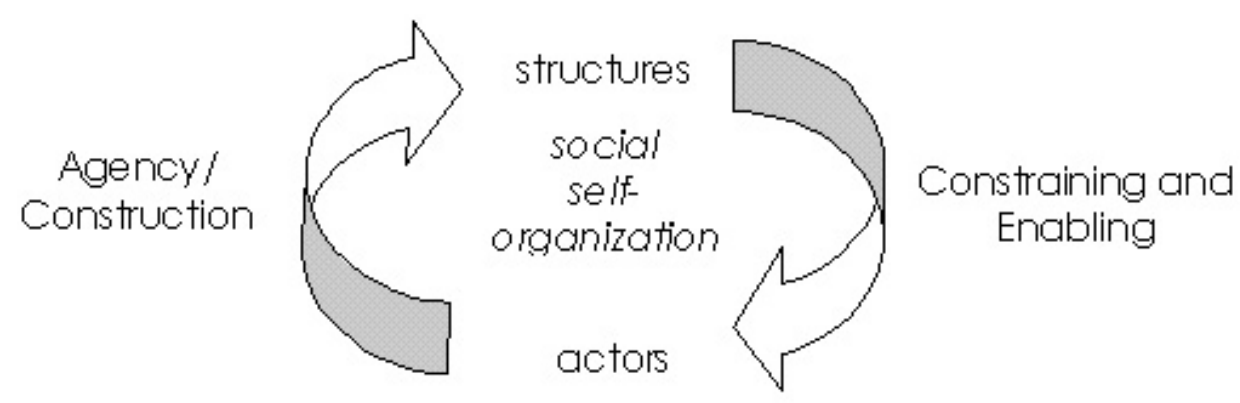

Fig. 1.: The self-organization of social systems ${ }^{3}$

Re-creation denotes that individuals that are parts of a system permanently change their joint environment. This enables the system to change, maintain, adapt and reproduce itself. What is important is that the term re-creation also refers to the ability of all humans to consciously shape and create systems and structures, an ability that is based on self-consciousness and, in Anthony Giddens' (1984) terminology, the reflexive monitoring of action. Societal systems are re-creative ones because they can create new reality, the socio-cultural human being has the ability to create the conditions for his further evolution all by himself. Creativity means the ability to create something new that seems desirable and helps to achieve defined goals,

\footnotetext{
${ }^{3}$ This model of social self-organisation was first introduced in Hofkirchner (1998) and elaborated in a number of further works such as Fuchs (2002a, b; 2003a-h; Fuchs/Hofkirchner 2003a, b, 2004;

Fuchs/Hofkirchner/Klauninger 2002; Fuchs/Schlemm 2004)
} 
it's a central feature of communicative action. The mutual productive process of re-creation describes the reflexive, self-referential nature of society in which structures are medium and outcome of social actions (Giddens 1984: 25f, for the relationship of Giddens' theory of structuration and social self-organization see Fuchs 2003c).

The information concept helps us to grasp the dynamics of self-organizing systems. Information is a process that exists as a relationship between specific self-organized units of matter, it is a relationship of reflection between a fluctuation that causes inner-systemic changes and the system's structure. A certain fluctuation causes nonlinear changes in the system, i.e. new order in the system emerges, the system changes its structure due to interactions of its elements. The fluctuating instability is reflected within the system's components, their relationships, and interactions. Reflection means that the system reacts to fluctuations and reproduces fluctuations in its inner structure as self-organized change. Information is not a structure given in advance, it is produced within material relationships. Reflection doesn't mean that an outside reality is mechanically copied or reproduced within the system, it means that a complex, nonlinear relationship between cause and effect is established in a self-organizing social system. All self-organizing systems are informationproducing systems.

In the case of a social system, we speak of knowledge as the social manifestation of information and the units of organized matter are active human (individual or collective) actors (Fuchs/Hofkirchner 2004). Knowledge is neither purely a subjective cognitive attribute nor purely an objective entity, it is a process and relationship between active human agents that participate in a self-organizing social system and co-ordinate their subjective knowledge in such a way that objective knowledge emerges. Knowledge is a manifestation of information in social systems that involves the interpretation, evaluation, and usage of data and can be found in various subsystems of society. It is a threefold process of cognition, communication, and co-operation.

The brain enables the subjective knowledge production of human beings (cognition). Cognition is a human activity and stands in relationship with an outside environment that is constructively reflected. Based on cognition, human beings enter social relationships where they communicate and co-operate in order to produce objectified knowledge structures that interact with and are mutually coupled to their subjective knowledge. Structures are totalities of durable and institutionalized behaviour. They can be found in all subsystems of society. Structures mediate communications and actions, they are medium and outcome of actions and communications. Structures are social relationships and objective knowledge in society. Social knowledge is a communicative relationship between actors where artefacts are included in order to produce sense and achieve goals. Knowledge as an organized form of data that are interpreted, assessed and compared, is contained in artefacts and social relationships. Artefacts store dead labour and knowledge about society, collective social actors (organizations) are an expression of the durable connectivity of human beings, they are shared spaces of living and working, and incorporate both interacting human actors and artefacts that the latter make use of. Social structures are media of society because they mediate social actions and communications. They store and fix knowledge and hence they simplify actions and communications because the foundations of these processes don't have to be newly produced permanently, they can be achieved by making use of structures. Hence by storing knowledge, social structures reduce social complexity. Structures are carriers of knowledge, they are the foundation of temporal and spatial extension of social systems. Social structures make possible a continuity of social reproduction across space and time, they result in the temporal and spatial distanciation of social relationships without the loss of continuity. 
Social structures are storage capacities in society which enable the existence of institutional forms which persists across generations and shape past experiences that date back well beyond the life of any particular individual. Structures also produce specific forms of contiguousness and hence they dissolve distances by reembedding social relationships that are disembedded in space-time. Social structures are a foundation of action and communication, they enable a certain degree of mobility, they mediate, organize, and co-ordinate social relationships and communications.

In re-creative, i.e. social systems, self-organization produces what can be termed objective social knowledge: The word "social" in the term that such a form of knowledge is constituted in the course of social relationships of several human actors. We consider the scientifictechnological infrastructure, the system of life-support elements in the natural environment and all else that makes sense in a society, i.e. economic property, political decision power, and the body of cultural knowledge, norms and values to be objective social knowledge. So we can distinguish five different types of objective social knowledge: ecological knowledge, technological knowledge, economic knowledge, political knowledge, and cultural knowledge. These forms store knowledge about past social actions and simplify future social situations because by referring to social knowledge the basics of acting socially do not have to be formed in each such situation. Objective social knowledge can be seen as a durable foundation of social actions that nonetheless changes dynamically.

Based on these assumptions, I will first discuss the synchronous level of scientific selforganization.

\section{Synchronous Scientific Self-Organization: The Self-Reproduction of Science}

Synchronous self-organization is based on a mutual relationship of structures and actors (3.1.), involves information production as a central feature (3.2.), includes the permanent emergence of new theoretical knowledge (3.3.), and has to do with various forms of truth (3.4.).

\subsection{Structures and Actors in Science}

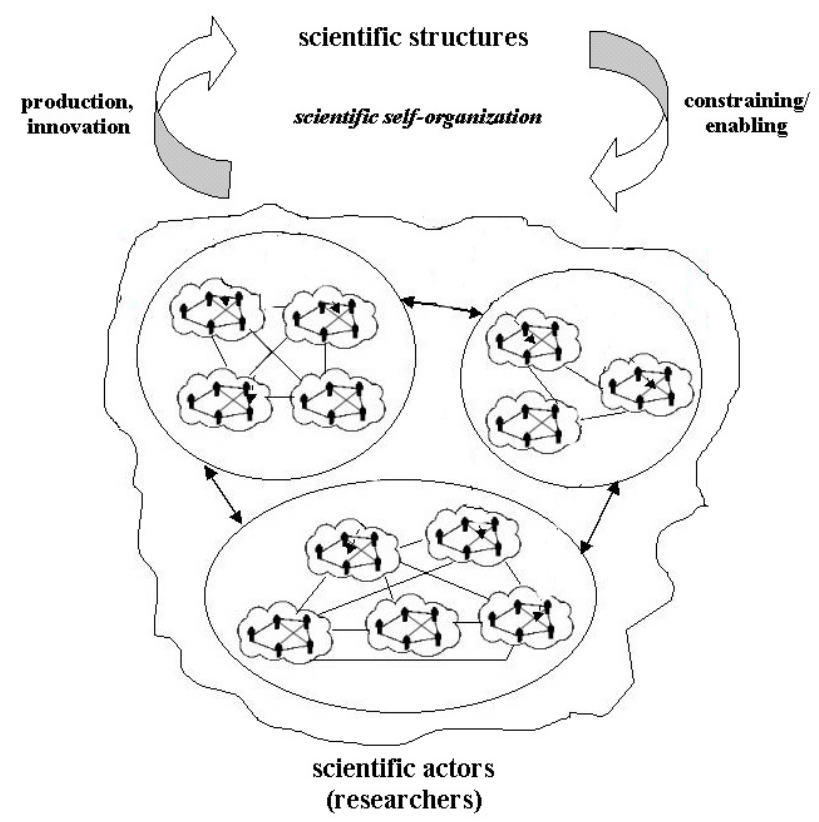

Fig. 2: The self-organization of science 
Synchronous self-organization of the scientific system is a process where scientific actors and scientific structures produce each other mutually. The actors enter social relationships by being active in research groups and the scientific community, as a result of this productive innovation process existing scientific structures are permanently reproduced and new ones emerge. Scientific structures enable and constrain research activities, they are a necessary condition of research and limit the latter's variety to a certain extent.

Scientific actors are both individual and collective actors. Research is a creative human process, theories that represent knowledge about the world are essentially a product of human creative activity. Hence focusing on the role of human actors and their relationship to social structures is crucial for describing science as a dynamic, self-organizing system. In research processes, human beings form relationships in order to explain and describe certain aspects of reality by making use of specific methods. Many of them organize in the way of research groups. A research group is a co-operative social relationship where human actors try to jointly work on a specific field of research and form their own infrastructure and identity in order to achieve this goal. The field of research can be disciplinary or transdisciplinary in nature. The scientific community is made up by the totality of scientists and research groups. It is subdivided into scientific disciplines and smaller disciplinary scientific communities. Research is not a closed, but an open process where scientists and research groups communicate, co-operate, exchange personnel, and compete. The totality of research groups and their interactions in a certain field of research makes up a disciplinary scientific community. Research communities and research groups from different fields communicate and co-operate, hence the disciplinary communities overlap and interact. In fig. 2 the actor level of science is represented by individuals organized in research groups, the latter interact and form disciplinary scientific communities that interact and in this process constitute the overall scientific community. Hence the four levels of scientific actors that form a systemic hierarchy are made up by the overall scientific community, (disciplinary and transdisciplinary) scientific communities, research groups, and individual researchers. Each level represents a system with emergent, non-reduceable qualities that is made up by interacting subsystems.

On the actor level science is a network of human actors. These actors are human because research is a creative human process, human creativity and innovation is the central guiding force of the research process. Hence we oppose conceptions of science that consider research as an actor network where actors represent human and non-human entities that make things. Bruno Latour (1987) and other representatives of Actor Network Theory misconceive science by conceptually blurring the differences between human beings and artefactual structures, the living social being and the non-social being. This misconception doesn't adequately distinguish between structures and actors and hence describes technologies in anthropomorphistic terms as having interests, acting in the research process, exercising power, etc. In order to avoid the reductionism of such an approach that doesn't recognize the emergent evolutionary qualities of systems and the differences between system types, it seems favourable to assume that there is both an actor and a structural level of science. These two levels are neither identical, nor fully different, they are dialectically interconnected, i.e. they are excluding and including/foreclosing and presupposing each other at the same time. This results in a mutual productive relationship between the two levels, the self-organization of science is based on circular causality and a dialectic of unity and difference.

Scientific structures are coherent relationships of humans and physical artefacts that are regularly reproduced and have a certain continuity in space and time. Structures are more 
durable, continuous outcomes of human practices, but at the same time they are the medium that makes social action possible. The most important scientific structures are theories, publications (articles, monographs, proceedings, research papers), technologies, patents, journals, institutes, faculties, universities, laboratories, research departments, research proposals, research reports, research programs, scientific associations, societies, and clubs; offices in scientific institutions, editorial boards, programme committees, etc. Due to the activities of scientific actors new qualities (e.g. new scientific papers) of these structures emerge permanently, science is a dynamic system where research practices produce and reproduce structures that produce and reproduce research practices. Scientific structures are medium and outcome of scientific actions. Hence research is a reflexive, circular causal, selfreferential process. The unity of science is constituted by permanent change on both the actor and the structural level, science is a system that permanently re-creates itself through human practices that result in the bottom-up-emergence of scientific structures and the top-downemergence of scientific practices. This mutual re-creation of structures and practices forms a productive loop that consists of two self-organization processes that are interconnected, presuppose, and produce each other.

There are several types of scientific structures (understood in the sense of Anthony Giddens as rules and resources of science):

1. Theories: Theories are results of research that represent systematic knowledge about the world.

2. Research institutions: universities, research departments (e.g. of corporations), faculties, institutes, scientific associations, societies, and clubs; editorial boards, etc. Such institutions (just like science funds) are themselves social systems made up of scientific and in some cases non-scientific actors (e.g. the non-scientific staff at universities) as well as various structures. For scientists these institutions are structural environments of action because they are durable outcomes of their agency and are a necessary condition of scientific practices that enables and constrains these practices.

3. Technologies: This includes both the instruments used for research as well as in the case of certain sciences technologies that are created as results

4. Journals

5. Publications: these are selective representational transformations of theories that are used for the dissemination of theories and for reaching scientific and non-scientific audiences(articles in journals and newspapers, books, talks, contributions in proceedings, research reports, research papers, etc.)

6. Science Funds: these funds are a connection of science to the polity and the economy, funding association as an interconnection of science, polity, and economy set research priorities and formulate research programs that function as basic rules and conditions of research

7. Norms, Values, Rules of Scientific Conduct: e.g. rules for submitting proposals and papers, presentation and participation rules at conferences, etc.

On the actor level, scientists engage in several different types of practices:

1. Innovation-related activities: These are all theoretical and empirical practices that are undertaken in order to achieve research goals, i.e. in order to produce theories that explain and describe certain aspects of reality. Theories are knowledge about the world that is produced in methodologically precisely defined ways. Scientific innovation is an activity of problem-solving, it tries to find solutions to problems that are defined by science and society.

2. Dissemination and interchange: Once new theories and new scientific knowledge are produced, they are made available to the scientific community, scientific knowledge gains 
a wider social reality in the process of dissemination and interchange. This includes the participation in conferences, congresses, discourses and discussions, workshops, scientific mailing lists and bulletin boards, the publication of research results in the form of articles submitted to scientific journals and conference proceedings, research papers, research reports, monographs; reviewing articles, organizing workshops, congresses, conferences, etc..

3. Funding-related activities: Research is mainly based on research projects that allocate material resources to research groups that allow the funding of innovation- and dissemination-related activities in a certain area of research. In order to be provided with financial funds that allow an appropriate level of scientific innovation and to gain reputation, scientists engage in writing project proposals that are submitted to science funds and in acting as reviewers of submitted proposals, they build national and international networks that work on certain topics and try to co-operatively submit proposals in order to do joint research.

4. Teaching: Education of students is another aspect of the scientific system, students are integrated into the scientific process by being confronted with research results. Scientists as educators focus on showing students learning how to learn and innovate in science. Scientific education is not a passive process where knowledge is transferred from scientific experts to students, but an active process where students learn how to actively reflect, criticize, and discuss existing scientific knowledge and how to individually and socially construct such knowledge. Science is an active encounter with topics that concern nature, hence one can only speak of real scientific education when students are treated as active, creative beings.

5. Public discourse: Scientists have an interest in reaching the wider public with their research results in order to influence social, economic, cultural, and political processes and to assure legitimacy of their work. Hence their practices include presenting results to the public by the way of public discussions, interviews, publicity activities, presence in the mass media, etc.

6. Science policy: Scientists, research teams, and scientific communities have political interests at the level of their group, their institutions, and of society. Hence they also organize as political actors that try to achieve certain goals in political processes. Political conflict can be found both within scientific organizations where different interest groups try to influence collective decisions of the organizations in certain ways and within the wider societal context where scientific organizations try to attain certain political goals that favour their institutions. Science is a system where power acts as a structuring force and produces phenomena of co-operation and conflict.

7. Economic practices: In certain fields of research results are patented and/or organized as technologies that are sold and compete on markets. This economic dimension in the form of transforming research results into commodities is not necessary an aspect of science, but due to the increasing economization of science it can be frequently found today. Other economic aspects include science-industry-partnerships and sponsorship.

These seven different practices of scientific actors can be further catagorized. The first four practices are essentially scientific practices, public discourse connects science to the cultural realm of society, science policy to the political realm, and economic practices to the economy. This shows us that science is not an autonomous, closed system, but that it has a relative autonomy that is based on the self-referential production of theoretical/scientific knowledge in a creative human self-organization process. This self-organization process is coupled to culture, polity, and economy, it receives inputs from these systems and provides outputs for these systems. Hence science is a subsystem of society that is in its self-organization mutually connected to the self-organization of other subsystems of society. Innovation, dissemination, 
funding-related activities, and teaching are the core scientific activities because they directly aim at producing new scientific knowledge, whereas the cultural, political, and economic practices of scientists have a more indirect scientific character, they aim at providing the infrastructure for scientific research. Hence scientific practices can be categorized as four distinctive types:

1. Genuinely scientific practices: innovation, dissemination, scientific interchange, fundingrelated activities, teaching

2. Cultural practices: public discourse

3. Political practices: science policy

4. Economic practices: Actions related to scientific knowledge as commodities, patents, science-industry-partnerships, sponsorship

The distinction between economic practices and funding-related activities is not clear-cut. Funding is always economic in the sense that it provides material resources that enable scientific innovation and dissemination. Funds can stem from industry, private sponsors (e.g. foundations), or public funding agencies. Economic processes in modern society are essentially capitalistic in nature, hence they focus on the accumulation of capital by producing and selling commodities. I prefer to speak of economic practices of modern science where a direct relationship between science and capitalist accumulation is established. Hence public and private non-profit funding are closer to scientific than to economic aspects, I use the term economic here mainly in the sense of activities related to capital accumulation. In the form of science-industry-partnerships funding-related activities and economic practices overlap, public and non-profit science funds are economic in the broad sense of the term that they provide a material foundation for scientific production, but they are non-economic in the more restricted sense of the term that focuses on capitalistic accumulation.

Historically scientific practices that focus on innovation and teaching have been organized as a unity within universities as institutions. With the shift towards informational capitalism, this unity is increasingly called into question and new scientific social systems are created. These are on the one hand industry-based research institutions that have direct economic goals as well as private institutions of higher education. This shift means that science changes its character increasingly from public to economic, science is increasingly strictly structurally coupled to the economy. The rise of capitalism has caused the disembedding of science and religion as one system and has produced a mutual interconnection of science and economic production.

Historically science has never been an autonomous system, it has always been structurally coupled to other subsystems of society. In premodern times science was quite closely coupled with the religious system, in modern times it is coupled to various subsystems, but the economic subsystem of society plays a special role. Public science is indirectly connected to the economy due to the fact that it needs to be financed, this relationship is mediated by the state which taxes labour and capital in order to enable its own self-organization (for the selforganization of the political system cf. Fuchs 2003d, 2004). The state in a negative feedback loop extenuates the self-organization of the economy (i.e. the self-referential production of capital, cf, Fuchs 2003b, Fuchs/Schlemm 2004) in order to provide a material foundation of its own self-organized operations. As a part of its own self-organization the state organizes the material infrastructure of public science by providing financial inputs. One foundation of the self-organization of the economy is an adequate level of qualification and skills of the workforce and the management. In Postfordism education is increasingly an aspect of economic organizations, but the traditional educational function of the scientific system still 
remains dominant. Hence in providing qualification the scientific system produces a basic foundation of economic self-organization, i.e. the self-referential accumulation of capital. The nature of the modern economy is not that it strives for producing capital, but that it strives for producing more and more capital, i.e. the accumulation of capital. One method for increasing profit and competitiveness is the increase of the productivity of labour, i.e. the development of new machines that allow a rationalization of production. Technology intensifies the externalization and appropriation of labour power. Economic rationality focuses on producing more commodities in a shorter time with less labour than at a prior moment. Economic rationalization is a necessary aspect of economic self-organization. In order to reduce complexity and focus on its own operation, the technologically mediated development of the productivity of labour is not an economic function, but a scientific function. Hence there is a division of labour between the scientific and the economic subsystem of modern society. In order to reduce the turnaround time of capital it is also necessary to improve methods of communication and transport. Hence the relationship science-technology also focuses on the establishment of media that allow an increased time-space distanciation of social relationships, science contributes to the establishment of technologies that mediate the globalization of social relationships (Fuchs 2003a). This economic function of the development of the factors of production is organized within the self-organization processes of the scientific system, it is fulfilled either by traditional public scientific systems or (increasingly) by private scientific systems (e.g. research departments of corporations). Science - and especially engineering as a subsystem of science - self-organizes the systematic production of technological knowledge that can be economically applied and objectified in machines that increase the productivity of economic organizations. In relation to the economy science in its self-organization has the strategic function of producing qualification and technology as outputs that are imported by the economic system in order to guarantee its selforganization. Science relieves the self-organization of the economy, it reduces the latter's complexity. The economy in an indirect process mediated by the state provides financial inputs for public science and education. Private research is either organized directly within economic organizations or as separate social systems that sell their knowledge as commodities to economic organizations.

Peter Weingart (2003) argues that science is (besides its relationship to the economy) also structurally coupled to polity and the mass media. Scientists would act as consultants in political processes, they write surveys and expert's reports for political institutions, and act as experts in advisory boards and advisory commissions (Weingart 2003: 89-102). Science would be self-referential and closed in the sense that the main public of scientists are the scientists themselves. In order to assure legitimacy in society and to increase their scientific reputation, scientists would try to translate their knowledge into a language that can be understood by a broader public, and they would present this transformed knowledge in the mass media (ibid.: 113-125). This process of mediation and translation would try to bridge the gap between science and society. The mass media are interested in topical news, science is one of their sources of information. The mass media are a medium for scientists to reach a wider public.

Whether science should be conceived internalistically or externalistically is an old matter of dispute in the philosophy of science. If self-organization is conceived in such a way that one considers self-organizing systems as closed, fully autonomous systems, speaking of the selforganization of science has to mean that the only developmental force in science is science itself and its quest for finding new truths. But such an internalistic conception doesn't take the social nature of science into account. Self-organized systems are open systems that exchange matter with their environment and are informationally connected to other systems. Hence the 
internal self-organization of science is only possible due to the interactions of science with other subsystems of society. The problem of internalism vs. externalism can be solved dialectically.

Herbert Hörz (1988) has argued that in a dialectical analysis of science a unity of internal and external factors of development would be possible. In such an analysis of science there would be the unity of scientific development and the material development of society, the unity of social needs and human problems, the unity of preconditions of creative personal development and their scientific usage under concrete-historical conditions. Society would be the framework of scientific development, it would not determine, but condition the possibilities and the real development of science. Relating this analysis to his concept of statistical law, Hörz argues that social conditions don't definitely determine the development of science and the personality of a scientist, but condition a field of possibilities

(Möglichkeitsfeld) for tendencies of development. Scientists and research groups would select according to further conditions possibilities that they realize from this field. A science type would be the concrete-historical type of the recognition of new relationships and laws of nature, society, consciousness, and human behaviour and of the transformation of discoveries into innovations by new technologies. The emergence of a new science type as a new higher quality of scientific development would be conditioned by theory and industry, internal and external factors of science.

Science is a power system in the sense that scientists are provided with different opportunities for influencing scientific decisions. This is inherently connected to the reputation of scientists as a form of social capital. Those scientists that have a high reputation, are present in the mass media, and are provided with the possibility to publish many articles in journals, are not necessarily those who write articles that have a high quality and a high degree of innovation. Due to the power structure of science and restrictive constraints set by society on science, it can indeed be the case that highly talented scientists with a high output and degree of innovation are not able to get a job in the scientific system or to receive rewards. Many talented scientists are excluded from the reward system and the scientific system.

"Some men whose accomplishments rank as high as those actually given the award will be excluded from the honorific ranks. Indeed, their accomplishments sometimes far outrank those which, in a time of less creativity, proved enough to qualify men for this high order of recognition. [...] Eminent scientists get disproportionately great credit for their contributions to science while relatively unknown scientists tend to get disproportionately little credit for comparable contributions. [...] The Matthew effect consists in the accruing of greater increments of recognition for particular scientific contributions to scientists of considerate repute and the withholding of such recognition from scientists who have not yet made their mark" (Merton 1968: 57f). Modern science is a system where recognition is power, it is stratified according to criteria such as gender, origin, and place. Groups like ethnic minorities, women, the Third world are marginalized within the social structures of science. Recognition as symbolic capital and a form of power can be converted into material capital in the sense that recognition increases the possibility of scientists and research groups that they will be provided with funds which in turn increases their recognition and excludes others. Hence there is a self-organizing power cycle in science that connects recognition and funds as symbolic and material aspects of science in such a way that powerful actors have good and to a certain extent increasing possibilities for accumulating both forms of capital at the expense of others. Bourdieu (1998) in this respect speaks of the mutual conversion of symbolic and material capital. The system of scientific recognition tends to become independent of innovative output, innovative knowledge is not necessarily produced by those scientists who 
have high recognition. A certain hypothesis will have higher visibility in science if it is introduced by a scientist of high recognition because his name will function as symbolic capital (it symbolizes quality and importance) that attracts the interest of other scientists who hope to increase their reputation by referring to and citing well-known names.

Pierre Bourdieu (1998) has argued in the context of discussing the importance of power in science, that science is a field of material and symbolic struggles that are oriented on the accumulation of symbolic (reputation) and social capital (social relationships). Modern science would have both an autonomous aspect where it functions according to its own logic of scientific conduct, and a heteronomous aspect where it is influenced by economic and political interests. It would be desirable to reduce the heteronomous influences in order to guarantee the autonomy of science so that it can gain a critical dimension.

The basic mutual relationship between structures and actors enables the production of information in scientific systems. I will now take a closer look at the informational aspects of science.

\subsection{Science as a Meta-Information System}

As far as I know Erhard Oeser (1976a, b, c) has been the first author who has described the connection of science, information, and self-organization. In his philosophy of science he has conceived science as a dynamic, self-organizing information system. I have my own interpretation of and view on why science is both a self-organizing and an information system. Heinz von Foerster has stressed that a self-organizing system is in close contact with an environment with which it is in a state of perpetual interaction (Von Foerster 1960: 221). "By a self-organizing system I mean that part of a system that eats energy and order from its environment" so that the system is "increasing [...] [its] internal order" (ibid.: 223). The system/environment-interaction is of crucial importance for both self-organization and information processes. Self-organizing systems are materially open, they are not closed systems, they receive inputs from their environment and produce outputs to the environment. If information is a dynamic relationship between systems that reflects certain stimuli, fluctuations, or perturbations within the structural organization of a meta-system in complex and non-linear manner, - i.e. information describes the dynamic process relationships between units of self-organized matter and all self-organizing systems are informationproducing systems -, then this means that when we speak about information we speak both about dynamic process relationships between systems and between a system and its environment. When we want to describe science as a self-organizing information system we hence must take into account the system/environment interaction of the scientific system.

Science means the systematic production of knowledge in the form of theories about certain aspects of the reality of nature and society with the help of precisely defined methods. Hence science is a system that deals with the production of theories which try to explain and describe reality. Research as a systemic practice identifies Particular and General aspects of the Individual, the Necessity of that which seems to be Accidental, the Essence of Appearance. Scientists use certain methods of cognition that are related to cognized objects in material reality in order to form knowledge about the world that helps them in achieving certain practical goals.

All self-organizing systems are information-producing systems. Information is a dynamic process of reflection where certain stimuli, fluctuations, or perturbations are reflected in a complex and non-linear way within the structural interactions and patterns of elements of a 
system. Knowledge is the manifestation of information in social systems that involves the interpretation, experience, evaluation, and usage of data and can be found in various subsystems of society. It is a social relationship between active, knowledgeable, selfconscious human agents. Talking about knowledge means talking about the most complex organizational level in the evolutionary world process that we are aware of - society. Knowledge is neither purely a subjective cognitive attribute nor purely an objective material thing, it is a process and relationship between active human agents that participate in a selforganizing social system and co-ordinate their subjective knowledge in such a way that objective knowledge emerges (Fuchs/Hofkirchner 2004). Knowledge is a triple social process of cognition, communication, and co-operation (ibid.). All complex systems are selforganizing information systems, all social systems are self-organizing knowledge systems.

Science as a system is in close contact with systems in its environment because these systems are its objects of analysis. Science orders the diversity of phenomena in nature and society according to defined methods, this process of ordering brings unity into diversity by representing certain aspects of reality in an ordered abstracted form. Systems in nature and society act as a sort of data for the scientific system, research processes establish an informational relationship between the scientific system and its environment in the sense that theories are complex, non-linear creative reflections of environmental processes. Signals from material and social reality are observed by the scientific system, scientists creatively construct theories that reflect this reality and constitute a new reality. There are numerous possibilities for representing environmental reality within theories, and indeed there are always various theories about the same aspect of reality that are related to each other in contradictory conflicting and subsidiary co-operative ways. This means that theory and reality are not connected in linear, 1:1 relationships, the interaction between environmental reality and scientific theories is complex and non-linear and it changes permanently as new aspects are added to theories, new theories and paradigms emerge, old theories vanish or become outdated, etc. Scientific reflection doesn't produce identical mappings of the objects of reflection, it produces these objects in new quality as new subjective reality. Concepts that make up theories are creative reactions of human subjects to their environment, but not linear "mappings" of reality. The term reflection refers to the fact that human beings are embedded into an outside world and interact with this environment. Scientific research and innovation is an information and self-organization process that produces knowledge about the world in systematic and methodologically defined ways. One specific aspect of this process is that the production of new scientific knowledge always involves the comparison of this knowledge to already existing knowledge, this relationship of comparison is one of criticism and synthesis.

Science focuses on theory production, hence it systematically produces knowledge about certain aspects of the world. Due to the fact that all complex systems are informational, one can say that science produces information about information systems, or knowledge about information systems to be more precise and to stress the societal character of science. Hence science is a self-organizing information system that operates on a meta-level by permanently producing information about information. This informational relationship between science and the information systems in nature and society stresses the dynamic aspects of both science and its object of study. Information is a term used for describing the process character of systems, i.e. the fact that these systems are not a static form of being, but permanently becoming and transforming themselves. The systems that science describes and analyzes are dynamically changing, they evolve by synergetic interactions of their elements. In describing the development processes of systems, i.e. the informational dynamics of systems, science produces knowledge in a self-organizing process: scientists observe and analyze the objects of research, i.e. certain systems, they interact and communicate in a social process that 
synergetically results in theories about certain aspects of reality. I.e. the informational dynamics of the objects of research are creatively and constructively reflected in a complex, non-linear way within the dynamic internal processes of science that result in theories, i.e. knowledge about the informational dynamics of observed systems. Science is a knowledge/information system in the sense that it produces knowledge about nature and society that is objectified in theories, it is a meta-information system in the sense that in its self-organization it produces information about information.

The relationship of subject-object in the scientific process has three aspects:

1. Cognition: In research human subjects establish a relationship to their human and social environment in the process of observation and analysis, the relationship scientistenvironment is one of creative informational reflection and objectification in subjective cognitive structures.

2. Communication: Scientists enter social relationships that constitute the scientific community, they compare and communicate their scientific knowledge. Scientific communication is a process of comparison where subjective scientific knowledge causes objective changes in the cognitive structure of other scientists. Each scientific conversation and each scientific book and article that a scientist reads, etc. causes a differentiation of his cognitive knowledge, whether this is one of criticism, acceptance, synthesis, etc. is an open issue that is determined by the whole social and individual history of the scientist.

3. Co-operation: In joint research scientists establish emergent knowledge in their shared environment that is a reflection and objectification of synergies that results from interactions and the productive relationship of portions of their subjective knowledge.

Each researcher, research team, research project, scientific research community, and scientific discipline operates its self-organization selectively in the sense that the object of research is a specific realm of nature and society. Each subsystem of science can't grasp the whole totality of real systems, it has to focus its attention on certain aspects, questions, and fields of research. Hence research is also a selective process of observation and description. Depending on which area of reality research is focusing, different scientific disciplines are formed and research teams belong to different disciplines. This means that in the self-organization of science certain subsystems are formed that concentrate their self-organization on relationships with certain parts of the natural and social environment of science. These subsystems describe, observe, and analyze only certain informational dynamics and form metainformation systems that have to selectively deal with information in the world in order to maintain and enable their self-organization. A scientific discipline analyzes processes that are an expression of a specific form of self-organization and movement of matter. In their selforganization, the humanities focus on the systematic production of knowledge about human systems, theological studies concentrate on the religious subsystem of society ${ }^{4}$, jurisprudence

\footnotetext{
${ }^{4}$ Theological studies are normally defined as the study of God. But such an understanding seems questionable because based on this assumption the object of scientific study is not part of society or nature, but is an absolute, unquestionable, transcendental entity. The problem with this assumption is that it is already a point of dispute whether such an object of study exists or not, whereas in all other sciences it is clear that the basic object of study can be imagined and analyzed. Categories like God and Spirit that are conceived as the Absolute, as something infinite and unquestionable and as absolute truth are not at all connected to the single sciences and to material reality. Religion is a system of belief, but not a science. If theological studies are understood as the study of God, than they are not a form of science, but a form of religion. It is not a scientific endeavour to try to find arguments why and that God exists, but it is a scientific task to describe the systems of belief of human beings, their embeddedness into society, and their development. Hence I would argue that theological studies are only scientific if they are understood and practically carried out not as a form of religion, but as the study of the role of belief and religion in society.
} 
focuses on law as a societal subsystem, economics on the economic subsystem, medical science on therapy and preservation of the human being as a system, the science of history on long-term development of human systems; musicology, literature studies, film studies, art studies, dramatics on certain art systems, anthropology on the fundamental biological, cultural, psychological, and linguistic constitution of human systems, pedagogics on educational systems, geography on spatial aspects of society, cognitive science and psychology on the cognitive system and its environment, political science on the political system, sociology on social systems and society as a system, communication science on communicational aspects of social systems, sport science on the morphology of human systems in movement, media studies on the role of media in systems, cultural studies on cultural systems, gender studies on the role of gender in social systems, agricultural science on the cultivation and fertility of the biosphere, engineering on technological systems, computer science on the design, application, usage, and assessment of computer systems, linguistics on language as an aspect of human systems, physics on physical systems, biology on living systems, astronomy on the universe as a system, chemistry on chemical systems, geology on the Earth as a physical system, meteorology on the atmosphere as a physical and chemical system, genetics on genetic systems, ecology on nature as a system and its preservation, botany on plants as specific living systems, logic on the form of systems of concepts, rules of knowledge representation and inferences in such systems, nutritional science on nutrition as an aspect of human systems, etc.

These scientific disciplines focus their self-organization on certain system types in nature and society or on certain aspects of such specific system types. The self-organization of science as a whole can only be achieved with the help of such a functional differentiation, the relatively autonomous self-organization of each discipline, and the interaction between the disciplines. One could say that all natural sciences are self-organizing scientific systems that produce knowledge about information because in natural systems not knowledge, but information is being produced. Then one would have to say that all humanities and social sciences produce knowledge about knowledge because knowledge exists only in human systems, but not in purely natural systems. But such a distinction between nature and society is dualistic. When we speak about nature we always speak about systems that are observed and changed by human beings, nature is part of society, for human beings there can be no observation of and encounter with nature from without society. Hence also all natural sciences produce knowledge about knowledge because when we analyze physical, chemical, and biological systems, researchers always have to analyze and observe them from a human perspective and have to take the relationship of nature and society into account. All systems that we describe in science affect the human being and are observed by human systems although in the case of many physical and biological systems the observed systems are much older than human systems, existed prior to human systems, and will probably exist much longer than humans and society. All sciences describe society as the system of observation that we can't escape from in relationship to other systems (or to society itself in case of the social sciences). Hence all scientific disciplines produce meta-knowledge, knowledge about knowledge in complex real systems that are described from within society.

Theories are systematic, generalized, abstracted, methodologically defined non-linear complex creative reflections of certain aspects of reality in nature and society. This means that research is a selective process and has to concentrate on the methodological analysis of certain aspects of reality. The formulation "nature and society" is neither exclusive nor inclusive in character, i.e. nature and society are neither fully different nor fully identical. Nature is the totality of systems in the universe and their interactions, it is material and organizes itself on various levels, i.e. it consists of various developing interconnected system 
types. Systems of one type are interconnected and connected to systems of other types, hence nature is relational and dynamic in character. Society is the realm of human activity and interaction, it forms one specific, small part of nature. But for human beings this small part of the universe forms their overall context of activity. All human activity and observation takes place within society, there is no position of humans external to society. Hence science as a system of observation and description of reality is also a part of society, it observes and describes processes from within society. It is not necessary to have an external position, a God-eye view, in order to make precise and well-founded statements about reality. All scientific activity and all theory-production are practices within nature and society. When scientists observe and describe systems, they do this within society. This means that also nature can like society only be described by human beings within society in social processes. Science is a social system, research is a social process. Nature as physical realm of activity of human labour, production, and communication is itself a part of society, in transforming and observing nature in economic, technological, and scientific processes, the human being integrates nature into society. Hence there is no relationship between nature and human beings external to society, all metabolic and observational processes that establish a relationship between nature and human beings function within society. Nature as human realm of activity is one subsystem of society that can be termed ecosphere. Nature has produced the human being and society as part of it, but the human being integrates nature as a subsystem of society into its own sphere of activities. Nature as part of society can be termed ecosphere. Hence when we speak about "nature and society" we speak about society as the total realm of activity on the one hand where we focus on social interactions between human beings and about the ecosphere as the interaction processes between humans and ecology and the interaction processes between physical systems that are observed by human beings. In the production of his life which includes the metabolism between society and nature and societal reciprocity, man as the universal, objective species-being produces an objective world (gegenständliche Welt) and reproduces nature and his species according to his purposes. All human beings are naturally societal, within the human realm nature is social in the sense that it is being changed and appropriated by human beings. Within nature there are qualitative differences which allow us a division into levels such as physical-chemical, the living and societal. In this relationship frequently only the physical-chemical and the living is seen as "nature" opposed to human society. We stress the unity in which the diversity is sublated, hence also preserved, nature and society are dialectically related (Fuchs/Schlemm 2004). Societality is our nature, nature is part of our society.

It seems to me that there are six scientific disciplines that have a more general character that needs to be characterized: philosophy, mathematics, information science/informatics, general systems theory, media studies, philosophy of science. Philosophy is a scientific discipline that has a more general character than other disciplines because its self-organization is focused on fundamental questions of existence of all system types. It doesn't focus on specific systems, but tries to reflect, discuss, and criticize the conditions of existence of all being. Philosophy deals with explanations of how single aspects of the world and single sciences are connected. It is the science of universality, the thinking study of material reality and the things that comprise this reality. It works out notions and categories in order to describe and explain the total world process on a general level. Areas of philosophy are ontology (What is the world and all being like?), epistemology (How do we perceive the world?), and axiology (How should we act in order to make to world a good place to live?). Philosophy connects, generalizes, and unifies single sciences on a more general meta-level. Hence it is based on the natural and social sciences, philosophical categories are related to the single sciences. E.g. categories like reason, love, human being are related to the humanities, categories like nature, space, time, matter are related to physics, etc. This also means that a category like God is not 
a philosophical and not a scientific category. Mathematics is a science that focuses on axiomatic systems, i.e. systems that are made up by logical connections of axioms. It deals with the logic of quantity, shape, and arrangement, it is a science of quantitative and spatial relations. The objects of mathematical studies are not real systems, but already abstractions of them. Quantities, shapes, forms, arrangements, distances, spatial extensions, etc. are aspects of all systems in nature and society. Hence mathematics deals with abstractions of systems. It is a meta- or general science in the sense that it deals with abstract and general aspects of systems and can be applied as an auxiliary means by all other sciences. Information science (see e.g. the contributions in Hofkirchner 1999a) or informatics (in a general sense of the term) deals with information processes in all types of systems, it focuses on information as a fundamental aspect of all complex systems and hence on their dynamic process character. Information science is transdisciplinary in nature because it understands information both as a general property of all systems and as a specific quality with emergent properties of concrete system types. It tries to show different and common aspects of system types, in its general meta-character of description it is closely related to philosophy and systems science as well as to the disciplinary sciences. General systems theory could be understood as a further metascience because it focuses on the transdisciplinary study of elements, structures, organization, behaviour, states, and development of phenomena that are described as systems.

Media studies are normally considered as disciplinary in nature and as focusing on the mass media as cultural phenomena. However, I have suggested that the term media can be interpreted in a much more general sense as an entity that helps organizing a relationship between two entities (Fuchs/Hofkirchner 2003a). Via a medium a relationship between parts of a system and/or system and environment is produced in order to enable the selforganization of the whole system. Etymologically the term medium stems from the Latin term medius which means in the middle, the middle one. Media have to do with mediation. Such a transdisciplinary concept of the media hence is intrinsically related to information science and suggests that the media concept shouldn't be confined to social and cultural systems, but be understood as a transdisciplinary category. Philosophy of science analyzes the methodological production of scientific knowledge, it is the science of the methods of scientific knowledge, it reconstructs the history of scientific concepts, and produces theories about the formation of scientific knowledge (Oeser 1976a: 15ff). This means that philosophy of science is the only science that operates its self-organization on a meta-meta-level. Whereas the other metasciences just mentioned go beyond disciplinary boundaries and have general objects of study, the object of philosophy of science is science itself. This means that within the meta-sciences philosophy of science has a special role, it is a science of science, a meta-meta-theory of knowledge. What does the term "meta-meta-theory of knowledge" mean? It describes the fact that philosophy of science produces systematic knowledge about knowledge about knowledge. As already pointed out the objects of study of all scientific disciplines are information systems, due to the fact that these systems are all embedded into society they form knowledge systems within society and when they are scientifically analyzed knowledge about knowledge is produced. Hence a science of science produces knowledge about knowledge about knowledge, it has a meta-meta-character, it generalizes generalizations, and abstracts the process of scientific abstraction. It is a $3^{\text {rd }}$ order knowledge system.

During the last decades transdisciplinary scientific research and projects have gained increasing importance. This type of research tries to bridge the gaps between the disciplinary fragmented sciences by starting intensive dialogue and co-operation between scientists that stem from different disciplines. Hence the research tasks are broad and general in nature and cover questions that can only be answered by applying both disciplinary methods/knowledge and transdisciplinary generalizations, communication, methods, and discourse.

Transdisciplinary research also operates on a meta-level and tries to combine more general 
questions and methods with more disciplinary concrete questions and methods.

Transdisciplinary research can be considered as a specific self-organizing discipline or subsystem of science that tries to interconnect all other subsystems.

Based on these findings, we can now take a closer look at how theoretical knowledge emerges in a self-organization process.

\subsection{The Self-Organization of Theory: The Role of Theoretical Knowledge in the Self- Organization of Science}

The permanent production and reproduction of theories by working out qualities of theories, criticizing other theories, devising completely new theories, synthesizing theories, referring to other theories, etc. is a central dynamical aspect of the self-organization of science. Theories are structural aspects of science, they are produced and reproduced through human creative activities and enable and constrain further scientific practices. Hence one can't say that the self-referential and self-organizing character of science is the production of theories by theories, i.e. a self-referential process where theories produce further theories or truths produce and reproduce further truths. Such formulations abstract from the fact that theories are not living systems that have the capability of acting on themselves, they only gain social momentum because they are produced by active human beings. Theories and truths are not autonomous subjects that can act and produce, they only gain their dynamic and selforganizing character in relationship with human actors. Hence it is important to stress that the self-organization of science is not a self-referential process in the sense that theories or truths are subjects, but that the self-organization of science is based on human subjects that enter social relationships in which they observe and describe certain systems, represent the results of these processes in theories and other structures that enable and constrain further scientific practices and relationships. Hence it is the relationship between scientific structures and actors that enables the self-referential productive character of science.

A theory is a system of logically interconnected and related hypotheses. A hypothesis is a statement about the lawful character of a certain aspect of the world, it explains certain real phenomena. Theory is always nonlinear in the sense that there are numerous ways of representing parts of outside reality creatively in a theory. Theoretical knowledge is an informational relationship between a reflected reality and a symbolic reality. A theory might deal with phenomena of reality not previously known, it might be a higher level theory than an older theory, it might synthesize older theories, it might try to solve problems an old theory created or left unanswered, it might try to expand a certain theory or school of thought, or it might analyze already known phenomena from a different angle or perspective than previously.

The scientific totality of theories is a whole that can be described as a large hypertext. A hypertext is a network of informational nodes that contain informational pieces and are interlinked. The hypertext has a distributed nature, it is essentially dynamic, fluid, transitory, it has no fixed place. Creating links is the essential operation of networking. A hypertext is a self-referential system in the sense that when a new link is created the system refers to itself by actualizing its content (for a discussion of the self-organization of the Internet cf. Fuchs 2003e). Each node of a hypertext refers to a number of other nodes that again refer to other nodes, etc. Self-referentiality is the essential nature of the hypertext, by creating links a hypertext is connected to a hypertext, the hypertext system is referring to itself. This selfreferentiality is based on human activities, i.e. on the creation of new hypertexts and links that are embedded into the existing system. The linked structure of a hypertext defines possible 
paths that are discovered by active human beings. "A hypertext is a matrix of potential texts, only some of which will be realized through interaction with a user" (Lévy 1998: 52). A hypertext system reproduces itself by the permanent self-reference of the category text:<smiles></smiles>

The metaphor of science as a grand hypertext refers to the self-referential character of scientific texts. A scientific text by the way of citation refers to other scientific texts, it incorporates part of the history of science, and methodologically discusses other texts. Hence the textual structure of science can be seen as a system that consists of textual nodes that are linked and form a complex system that has as many entrances as nodes and almost unlimited possible readings. Browsing this system means to discover references in scientific texts and to direct ones attention to these links. Writing a scientific text means to insert a node into the complex web of science and hence to contribute to the self-organization of the scientific system by establishing nodes and linking these nodes to other already existing nodes. The phenomenon of citation shows that science is a communication system where actors refer to the outputs of other actors, citations document the perception of certain ideas by scientists as well as their reactions.

Classically induction and deduction have been conceived as two opposing forms of reasoning. Induction can be understood as reasoning from empirical data to general principles, from the individual/particular to the general/whole, it infers the whole from individual observations. Deduction can be defined as reasoning from general principles to empirical data, from the general/whole to the individual/particular, it deduces individual cases from general assumptions. This dualistic opposition of induction and deduction and of verification and falsification has survived in the philosophy of science until today and has been assisted by famous figures and influential theories of science such as Karl Popper's critical rationalism. Inductivism goes the way from empirical experiences to hypotheses, deductivism the way from general hypotheses to empirical experiences. These seem to be two different ways of relating experience and theory. Such a dichotomy is unsatisfying because hypotheses are not unfounded and pure suppositions, but always based on experiences with society and nature, and all empirical observation is not pure experience, but always influenced by theoretical assumptions.

In order to overcome such a dichotomy, scientific reasoning and the formation of scientific knowledge can be described as a double-process of induction and deduction where scientific knowledge consists of both empirical knowledge and theoretical knowledge and is formed in loop that consists of two self-organization processes (fig. 3, cf. e.g. also Oeser 1976c: 119f, 1988: 102-131; Krohn/Küppers 1989: 46-65, 1990: $213 \mathrm{f}^{5}$ ).

\footnotetext{
${ }^{5}$ Oeser conceives the self-organization of scientific knowledge as a dialectical, mutual productive process between theory and information, Krohn/Küppers as a dialectical, mutual productive process between theory and method. Both conceptions are quite similiar in the sense that they stress the circular causality in the selforganization process that can be attained by recursive links between theoretical and empircal aspects of research.
} 


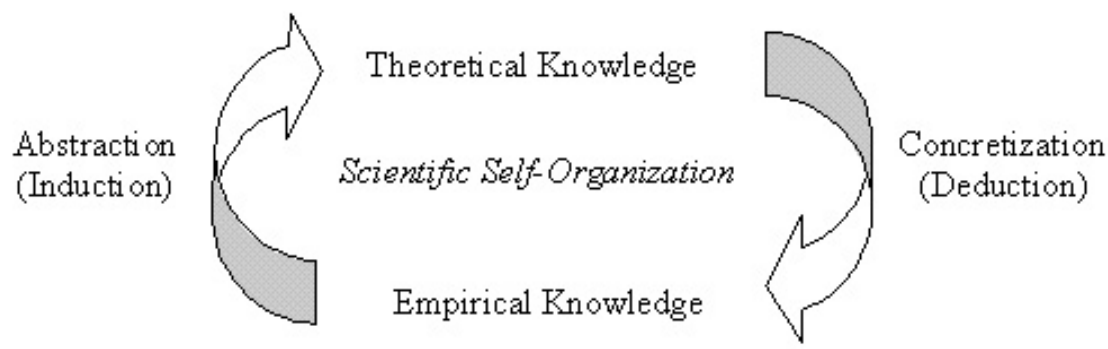

Fig. 3: The basic self-organization process of scientific knowledge

All formation of scientific knowledge contains both theoretical and observational aspects, it is grounded both in rationality and experience. Theory and experience are mutually connected, theory is tested by observation and observation changes theory. The deductive logical step from theory to experience means on the one hand that theories can be tested empirically and on the other hand also that all observation is based on theory, i.e. all formation of empirical knowledge is conditioned by the theoretical knowledge scientists have acquired earlier on. The inductive logical step from experience to theory means on the one hand that empirical observations can be generalized in the form of hypotheses that can be logically interconnected in the form of a theory and on the other hand also that all formation of theoretical knowledge is based on the totality of experiences and observations scientists have made earlier on. The formation of scientific knowledge is a double self-organization process where new theoretical knowledge emerges from empirical knowledge in a bottom-up-self-organization process and new empirical knowledge emerges in a top-down-self-organization process. Various scientific methods differ from each other according to the degree that they stress theoretical or empirical knowledge, nonetheless all scientific methods and all scientific knowledge are based on both experience and theory. If one compares e.g. the philosophical method of reasoning as a method more grounded in theoretical knowledge to the qualitative interview as a method of the social sciences that is more grounded in empirical knowledge, one will see that the degrees of experience and theory employed here differ, but both methods are based on empirical as well as theoretical knowledge. Philosophical reasoning can formulate and reformulate theories only based on observation of the world, qualitative social science can approach its field of research empirically only based on hypotheses that should be tested or reformulated.

Already Karl Marx (1857) described this dialectical character of scientific knowledge when he characterized scientific reasoning as advancing from the abstract to the concrete. The abstract orders certain entities according to common aspects, with abstraction something looses its ground in reality to a certain degree. But the concrete is the starting point of all thinking, it "is the real point of origin, and thus also the point of origin of perception and imagination" (Marx 1857: 35). To abstract from the concrete means to order different entities according to their common aspects, the abstract "emphasizes and defines the common aspects and thus avoids repetition" (ibid.: 20f). The concrete is more rich in expression, the "concrete concept is concrete because it is a synthesis of many definitions, thus representing the unity of diverse aspects" (ibid.: 35). We can approach the concrete with the help of abstract categories, this approaching helps us in again abstracting from reality and forming abstract categories. Marx has called this method of reasoning the "method of advancing from the abstract to the concrete" (ibid.: 35).

For Marx even the most abstract categories are results of concrete historical relationships and abstract categories are formulated based on concrete real relationships. The most general abstractions could only be developed based on rich developments of the concrete real: "The most general abstractions arise on the whole only when concrete development is most 
profuse, so that a specific quality is seen to be common to many phenomena, or common to all" (Marx 1857: 38). Scientific knowledge as the unity of experience and theory is grounded in the richness of concrete experience and reality of sensual living human beings, these experiences allow rational abstraction and the induction of abstract categories, with these abstract categories reality can be reapproached, changed, and observed, experience changes, i.e. its richness is further enhanced which allows the continuation of the abstraction process, etc. Hence the self-organization of scientific knowledge can also be philosophically described as a dialectic of the abstract and the concrete.

The Abstract is an order of the Concrete, it has certain emergent qualities that connect singular concrete phenomena of reality. The Abstract is a sublation of the Concrete, it has new qualities that are constructed by the human activity of cognition. Knowledge reflects concrete phenomena of the world process in such a way that certain aspects of these phenomena are left out, whereas others are ordered according to certain criteria that are used as measure of the ordering process in order to single out common aspects that are expressed in the form of new categories. Categories that reflect common essential aspects of real phenomena make up the emergent qualities of the abstraction process. The abstracted result of reflection has eliminated certain aspects of reality, preserved others, and contains new qualities of a higher order reality, it is a sublation of concrete reality. The Abstract allows us to reapproach the Concrete as experienced reality, i.e. to have new experiences of the world and society based on existing systems of categories and thinking. The Concrete as an object in nature or society is the historical result of manifold differentiations and self-organization processes, it is not identical with the experienced Concrete. There is a difference between Being and Consciousness, between the Real Concrete and the Experienced Concrete, the Material and the Ideational. Advancing from the Abstract to the Concrete as a cognitive process doesn't constitute the Real Concrete, it constitutes the experience of the Real Concrete. Only practices based and connected to cognition change the Real Concrete. To recognize the Real and to form knowledge of the Real is a foundation of practically changing the real, but it is not the process of changing the Real itself. Consciousness as fundamental aspect of a human system is part of the practical production of material reality in social relationships, it is the foundation of cognition and communication, but only as unity of these three aspects can the practical human changing of nature be explained. Consciousness is reflection of reality, ig is part of the production of reality. Cognition is part of practice, but not identical with practice. 


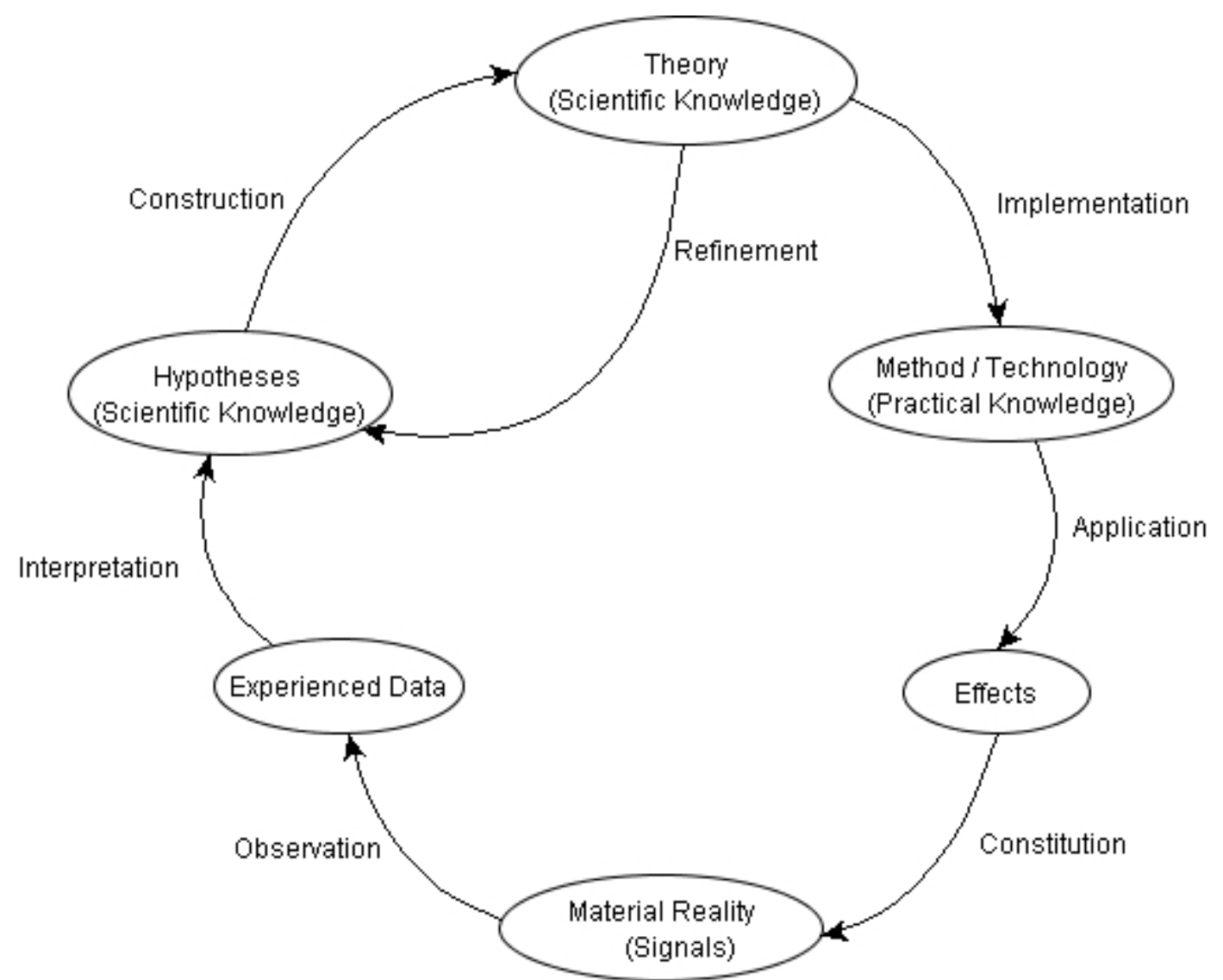

Fig. 4: The full cycle of the self-organization of scientific knowledge

The production process of scientific knowledge that can be characterized as a dialectic of induction and deduction or as advancing from the abstract to the concrete, can be further analyzed as a self-organization cycle (fig. 6). This cycle connects material reality and the consciousness of scientific actors. Certain phenomena in nature or society are observed by the scientist(s), they function as signals that result in basic experiences, perceptions, observations. Signals are taken up by the sense organs, connected to the brain via the CNS, and integrated into a whole (perception, observation, experience) by the brain. Cognition is a constructive process that reflects material signals and actively and autopoietically transforms these signals into knowledge. These basic cognitive wholes/realities can be termed experienced data. The data elements are integrated and interpreted, hypotheses as a form of scientific knowledge that make statements about the observed reality and hence are a complex, nonlinear reflection of material reality emerge. Hypotheses are logically connected in order to construct theories, new hypotheses are integrated into existing theories, etc. Old theories are sublated in the Hegelian sense of the term Aufhebung. This means that new higher qualities of a theory emerge in the permanent self-organization and self-reproduction of scientific knowledge. The emergence of new hypotheses can result in the refinement of older hypotheses. Theories and concepts are medium and outcome of human action, they enable and constrain human practices, but are the produced result of human interaction in society and nature. In order to connect theory to outside reality and to observe whether it is formally, adequately, discursively, and practically true, theories are transformed into methods of observation and testing. All methods are technologies of experience and observation, they are a form of knowledge that connects theories to practice, hence we can speak of practical knowledge. In certain areas of science (especially engineering and the natural sciences) theoretical knowledge can be implemented and objectified practically in the form of machines. Hence technology here also means that applying theory can result in machinery that is used in other organizations and subsystems of society in order to achieve certain goals and interests. The 
application of methods is a practical aspect of science that changes material reality, it has effects in the outside environment of the scientist(s). These effects are an aspect of material reality and as such an aspect they change reality, nature, and society to a certain extent. Hence science is always effective in the sense that it changes its social and natural environment. In the knowledge-based society, applied scientific knowledge has tremendously changed nature and society in both positive and very problematic ways. The application of theories is a testing of their truth, this testing should not limit itself to aspects of correspondence with reality, coherence, and discursive communication, also practical truth should be taken into account by science as one of its aspects of application. The contribution of science to the production of global problems shows that frequently practical truth has not been considered as important aspect of science by scientists. Ethical responsibility is a central criterion of the self-organization of science.

In the self-organization cycle just described there is the bottom-up-emergence of theoretical knowledge and the top-down-emergence of experiences and material effects. Research is a cyclical process with different entry points, it neither consists solely in bottom-up-induction or -abstraction, nor solely in top-down-deduction or -concretization, it is a complex, nonlinear, cyclical, dialectical process where old theoretical knowledge is permanently updated/reproduced and changed in the sense that new higher knowledge emerges, old knowledge is eliminated or integrated into refined theories, and where new experiences emerge based on existing experiences and theoretical knowledge. It can be the case that one method is applied several times or that it is redefined in order to gather precise observations, if this is done the whole loop is traversed several times: After the methods has been applied once, material effects will be observed, the emerging data will be compared to theory (although theory must not necessarily be changed) and method, the method will be redefined and will again be applied and result in new effects that can be observed, etc. Embedded in and in interaction with material social and natural reality, the self-organization of scientific knowledge mutually connects and produces experiences and theory in processes of bottomup-abstraction and top-down-concretization that have emergent outcomes. The cyclical nature of this process means that there are permanent sublations of old knowledge and experiences, certain qualities of theory and experience are preserved, others are eliminated, new qualities emerge, the whole system enters a new higher level of development. Hence that this process is cyclical doesn't mean that its outcomes are identical, the identity of scientific knowledge systems can only be reproduced by the permanent self-organized production of difference. The development path of scientific knowledge is a spiral with the production of new higher qualities and permanent difference: EX1-H1-T1-M1-E1-EX2-H2-T2-M2E2....(EX..experiences, H...hypotheses, T...theory, M...method, E...effects).

Cognition is a threefold self-organization process (Hofkirchner 1999b; 2002: 103-124; Fuchs/Hofkirchner 2004). At first, signals from the environment are perceived and transformed into data, then data are interpreted, knowledge emerges as interpreted data, finally knowledge is evaluated, it gains a practical dimension that is oriented on problemsolving, it is transformed into practical knowledge. Data are stimuli that are perceived from the environment, but they are not a form of knowledge. Knowledge is formed on the second and third level, it always involves interpretation and evaluation. In the self-organization process of scientific knowledge the triad data - knowledge - practical knowledge can also be found: Observations as basic data emerge from material signals, they are interpreted and integrated into existing theoretical knowledge, new scientific knowledge (hypotheses, theoretical knowledge) emerges, theory is implemented and applied, practical knowledge in the form of methods and technologies emerges. 
The metaphor of science as a grand hypertext (introduced above) also refers to the transformation of science in the knowledge age towards "cyberscience". The complexity of science increases massively and indeed exponentially. This is partly due to the continuous progress in information storage, processing, and manipulation that has gained a massive boost by the introduction of the computer as a medium that enhances science. The computer and electronic databases allow to manage this phenomenon of being lost in scientific hyperspace, i.e. electronic scientific databases enable us to index, categorize, and search parts of the grand scientific hypertext.

Networked computer usage has resulted in a real-time globalization of social relationships, knowledge flows today transcend national borders, they result in the globalization, intensification, and time-space-distanciation of social relationships and establish a more intensive and extensive interconnection of humans. New knowledge-based technologies like the computer facilitate the delocalization and disembedding of communication in the sense of the generation of spatial and temporal distance. One of the main characteristics of knowledgebased technologies is that they increase the speed of delivery of data massively and hence are a medium of the time-space distanciation of communication. This means that with the help of computers scientific communication has been restructured, the computer and the Internet have become important scientific communication media that allow new forms of scientific manyto-many dialogue, computer-supported co-operative research, the globalization of scientific communication, an interactive and a multimedia dimension of scientific knowledge, and an increased speed of delivery of scientific knowledge.

Traditionally the production of scientific knowledge has been based on linear texts that are transmitted in the form of lectures, talks at conferences, articles, and books. The interactive element was mainly confined to workshops and conferences. This traditional setting is characterized by a lack of co-operation and interaction. New electronic media can enable new possibilities for the production of scientific knowledge: many-to-many communication, multimedia, hypertext, and interactivity. Virtuality can foster interactive and many-to-many scientific communication by making use of discussion forums, mailing lists, e-conferences, and computer-supported co-operative research. It can employ multimedia and hypertext in order to present knowledge about knowledge in visually attractive forms. By making use of such electronic methods, science and society could create a participatory, co-operative environment of self-organized scientific knowledge production. In this respect I consider ejournals and e-libraries as being of particular importance because they can try to contribute to a solution of problems of traditional scientific dissemination such as the slow pace of publication, limited availability, access, and diffusion rate; the high costs of publications, the limited visual attractiveness of scientific texts, etc.

Technologies are means and methods that the human being uses in order to appropriate and change nature in such a way that it can achieve certain defined goals. Hence two specific characteristics of technology are that it is a means to an end and that it mediates a metabolism between society and nature. Technologies are medium and outcome of social practices, they are connected to human labour, interests, communication, knowledge, power, norms, values, and ideologies. The usage of technologies in order to produce goods that satisfy human needs is part of the economy, science and technology are connected because certain applied sciences construct and reflect methods for building and using machines. Constructing scientific knowledge is a process of reflection and objectification; human cognition, communication, co-operation, and labour as aspects of scientific practice are objectified in theories as products of science, theories reflect and objectify the thinking relationship of human beings to nature. If scientific knowledge is applied economically, new technologies can be the outcome. 
Technologies are practically applied scientific knowledge, they are an objectification of scientific knowledge, an objectification of results of scientific objectification and reflection. Hence technologies are constructed in a process of $2^{\text {nd }}$ order objectification (objectification of objectified scientific knowledge). This is a process that is accomplished by human subjects in economic relationships.

Scientific reflection is a social process, learning to know nature and society can never be achieved individually, it is done in relationship with other human beings, and based on the scientific knowledge that already exists. Scientific reflection can't exist without the object of reflection, those entities in nature or society that are objects of analysis and observation. Hence scientific knowledge is a process that establishes a connection of the scientist with nature and society. That scientific knowledge is a process of reflection means also that the totality of knowledge in society evolves historically in such a way that old knowledge is part of actual human experiences and practices that result in the production of new knowledge. Knowledge has a social and a historical character, knowledge production is done within society in a social process and based on the history of knowledge. The scientist selects parts of the historically produced scientific knowledge as a foundation of his own practices and knowledge. Scientific knowledge has its own history that has been produced by human beings, Newton's statement that "If I have seen further it is by standing on the shoulders of giants" refers to this historicity of knowledge.

The social character of knowledge has already been analyzed by Marx who spoke of the General Intellect as "general social knowledge“" (Marx 1857/58: 602) and of "universal labour": "Universal labour is all scientific labour, all discovery and all invention. This labour depends partly on the co-operation of the living, and partly on the utilisation of the labours of those who have gone before. Co-operative labour, on the other hand, is the direct co-operation of individuals“" (Marx 1894: 114).

Besides its idealistic, functionalistic, conservative and reductionistic character that is based on the assumption that all scientific development is determined by the adherence of individual scientists to certain values, Robert K. Merton's analysis of science is right in pointing out the historicity of scientific knowledge and speaking in this respect of "communism". Scientific knowledge would have to be a public good because it would be produced co-operatively in a social process and would be based on a common historical heritage of knowledge. "The substantive findings of science are a product of social collaboration and are assigned to the community. They constitute a common heritage. [...] Property rights in science are whittled down to a bare minimum by the rationale of the scientific ethic. The scientist's claim to "his" intellectual "property" is limited to that of recognition and esteem which, if the institution functions with a modicum of efficiency, is roughly commensurate with the significance of the increments brought to the common fund of knowledge. The institutional conception of science as part of the public domain is linked with the imperative for communication of findings" (Merton 1973: 51). The social and historical character of knowledge should be acknowledged and preserved by science. With the transition to informational capitalism, the opposite seems to be true: Scientific knowledge is increasingly treated as a commodity and patented as intellectual property. Hence the essence of knowledge is not taken into account, the actual individual appropriation of knowledge contradicts the public, open, social, and historical nature of knowledge.

The self-organization of theoretical knowledge is closely related to the production of truth. The role of truth in scientific self-organization will now be analyzed. 


\subsection{The Role of Truth in the Self-Organization of Science}

Speaking about the relationship between scientific theories and environmental reality as a self-organized information process means to assume that systems are real and can be described and analyzed in scientific processes. Science is not mere speculation and pure fictious construction of reality, it is the production of methods of observing, analyzing, and describing nature and society that result in theories that claim to represent real systems and their development processes as they are in the form of abstracted, generalized principles. In order to make scientific cognition possible and to avoid solipsism, scientists have to assume that systems are real and can be analyzed, observed, and described by human beings. This doesn't mean that a scientific theory automatically represents reality as it is, but that there is an objective reality that can be observed, analyzed, and described and that all theories claim to represent reality as it truthfully is. Hence truth understood as the assumed correspondence between concepts and material reality is a central aspect of science: theories argue that they represent generalized and abstracted principles of the functioning of certain aspects of reality and that the objects of analysis really function according to these principles. Each theory is a truth claim, but one that is based on a systematic methodology, permanent evaluation and correction, and conflict-based discourse. Hence scientific truths are not absolute truths, they are truths-in-question, truths-in-discourse, and truths-in-conflict, and truths-in-development.

Scientific knowledge is not static, it is dynamic and in permanent development. The objects of research as well as scientific tasks change, new aspects of theories and entirely new theories have to be produced permanently because of the dynamic change of science, nature, and society. This means that researchers permanently compare their theories to the development of the systems they try to describe, to the scientific state of the art, and to other theories. They discover errors and missing aspects of their knowledge, and hence permanently reformulate theories. Theories are not static texts, but permanently becoming texts, a form of being that redefines itself dynamically, a reality that is in close contact to other realities and changes according to the dynamic becoming of the world process. The regularized scientific processes - developing methods of description and observation, permanent empirical observation of the objects of research, self-criticism, reflection, review procedures, scientific discourse and conflict, etc. - guarantee the dynamic and plural character of scientific truths.

We can distinguish different types of scientific truth. A theory is adequately true if during a certain period of its own existence it corresponds to reality and seems to adequately explain reality. It is formally true, if it is logically consistent. It is discursively true if a certain community agrees in consensus that they agree with the statements of a theory. Discursive truth is always relative, it reflects the dynamics and struggles that are connected to scientific development. There will never be absolute discursive truth in science, a situation where all scientists agree with a certain theory - critique, discourse, conflict, and contradiction are driving forces of scientific development. Adequate truth is also contested in the sense that permanently scientists question and criticize other theories and theories are frequently redefined in order to deal with new problems and aspects of reality. This shows that the struggle for adequate truth is a fundamental internal development force of science.

These forms of truth are just the preconditions for a higher form of truth that I consider as the most important type, practical truth. Practical truth is a process where practice is considered as the criterion for truth, it is connected to the concrete practical relationships between human beings and between human beings and nature, i.e. to dynamical change in society and nature produced by the human being in active relationships. Practical truth is not abstract, but concrete. In practical human relationships scientific knowledge can be successful or 
unsuccessful, practice is an assessment of the truth of scientific knowledge. This statement should not be misunderstood as functionalistic or pragmatic concept of truth that argues that only such knowledge is true that functions in reality, i.e. that can be directly applied in certain subsystems of society. Practical truth has a much more ethical dimension, it is connected to fundamental human rights, to good society, to human progress, wealth, and well-being for all. It has to do with the power- and class-structure of society. One can imagine situations of absolute societal truth where there is happiness, well-being, and wealth for all. Science can and indeed tries to make contributions to approaching such an absolute truth, but it doesn't linearly or automatically produce human progress or human misery as advancement towards or separation from truth. There is no automatic progress or approximation towards or separation from absolute truth by science or society because social systems are human action sytems that are non-deterministic and hence governed by the chance of free human activity that is conditioned by social structures. Science is embedded into practical social struggles, in modern society it has itself an antagonistic character: it contributes both to the rapprochement of and distanciation from absolute truth. Hence practical truth is relative in character. This relative character means also that relative to the potential and social forces of a specific mode of societal development or historical epoch, a certain degree of absolute truth is possible. Knowledge of the world can't be the same at all instances of history, it depends on the historical development of society and the forces that shape this development. Knowledge and truth are historically evolving. That practical truth is connected to absolute truth doesn't mean that there are unhistorical, teleological absolute determinations of development, but that there is an essence of societal existence that is defined by the social and co-operative nature of the human being and of human systems and that can be approached by human beings or that they can depart from. Frequently approaching absolute truth and departing from it are even simultaneous, antagonistic processes. Approaching and departing are practical social processes, hence truth is practical and historical, it is a process.

The concept of practical truth points to the relationships of science with production, power, and ideology. It is not itself an ideology because it critically reflects concepts of science that argue that science is value-free, it tries to explain the ideological character of abstract and neutral concepts of science and argues that all science is connected to human conflicts and power relationships. It sees itself as a deconstruction of dominating ideologies and of ideological aspects of science, it is a critical self-observation mechanism of science and society. Ernst Bloch (1963: 162-185) has argued that the fact that history and society are open and can be changed are important aspects of truth. Hence a practically true theory doesn't simply explain how things are, but how they can be changed for the better, it recognizes being as process that can be changed and as being-in-possibility, it takes into account that the world is full of not-yet being. For Bloch practical truth has to do with changeability, openness, notyets, struggles against estrangement/alienation, concrete utopias, active hope, really possible futures. Similarly to Bloch, Herbert Marcuse has defined a criterion of practical truth. Knowledge would be true if it is "in accordance with the real possibilities open at the attained level of the material and intellectual culture", it offers "the prospect of preserving and improving the productive achievements of civilization", and contributes to the "pacification of existence" and the "free development of human needs and faculties" (Marcuse 1964: 220). Marcuse points out that the practical truth of knowledge has to do with the question whether or not it contributes to the realization of open, progressive possibilities of a society and to the achievement of material and intellectual freedom. Science is not only a human process, it should also be a humane process that advances humanistic goals.

The notion of practical truth has always been of high importance in Marxism. Due to the existence of global problems today we are in a situation where science can no longer be an 
ivory tower of experts who declare absolute truths, hence the Marxist notion of practical truth gains importance because science should be judged according to the way it contributes to the production and solution of social problems.

Bloch (1975: 248-253) also argues that practical truth is not only related to the relationships between human beings, but also to the relationship of man and nature. Knowledge and applied knowledge (technology) would have to establish a friendly and sustainable, not a destructive relationship with nature in order to be true. Hence science would have to contribute to the establishment of an alliance between man and nature and of an alliance technology in order to be true. The concept of practical truth shows that scientific knowledge should be sustainable, co-operative, and participatory in a very practical sense: it should contribute to the preservation of nature and the well-being of human beings. In modern society science is a productive force in the sense that it has by developing the technological forces continuously diminished the amount of necessary human labour and hence has contributed to establishing the possibility for a realm of freedom where human beings can live in wealth and enjoy a maximum of free time and leisure. Hence it contributes in this sense and a lot of other ways to the achievement of fundamental human values. But modern science is also a destructive force that has rationally developed possibilities of the destruction of humans by humans and the destruction of nature by humans. Technologically inflicted misery and unemployment, the ecological crisis, the arms race, the nuclear threat, weapons of mass destruction, etc. show the threat that science can pose for society and its contribution to global social problems and risks. Our specific societal situation is characterized by a schizophrenic antagonistic situation: Science and technology have advanced the productive forces to a point where well-being and wealth for all seem to be possible due to the productive technological capacities, but at the same time these forces have a destructive dimension that poses the threat of the total extinction of society and nature on Earth. Aspects of practical truth in science seem to be necessary in order to point towards the ethical dimensions of science, we need a science that is a science for all and that advances human rights, freedom, participation, well-being, wealth, peace, co-operation, and sustainability.

Research tries to identify and contribute to the solution of human problems, in the practice of problem-solution it produces knowledge and non-knowledge, it produces problem-centred knowledge, but it also produces new problems that represent non-knowledge about the world. Modern science produces both knowledge and non-knowledge, knowledge creates nonknowledge, in the knowlede-based society (KBS) this dynamic is of special importance because scientific-technological progress results in a number of unpredictable uncertainties of development, i.e. modernization risks. These risks threaten to get out of control, Helmut Willke speaks in this context of a crisis of knowledge (Willke 2002). The increased influence of scientific-technological knowledge on our lives has resulted in an increased fragility of society and nature (Stehr 1994). Risks arise a side-effects of a form of modernization that is "blind and deaf to [...] [its] own effects and threats" (Beck 1994a: 6), the KBS is a high risk society. Ulrich Beck argues that side-effects of modernization like the destructive power of modern technologies and environmental degradation are an expression of non-knowledge. Non-knowledge would be the medium of reflexive modernization (Beck 1994b, 1996). The more modern a society, the more knowledge-based and risk-intensive it would become (Beck 1996). There would be two forms of non-knowledge: something that one doesn't want to know (Nicht-Wissen-Wollen) and something that one can't know (Nicht-Wissen-Können) (ibid.: 300, 302). Further dimensions of non-knowledge would be selective reception and distribution, uncertainty of knowledge, and mistakes/errors. All decisions in late modern society would be confronted with uncertainty, even expert knowledge. But to a certain extent one could try to manage risks by reflecting non-knowledge, learning to know that and what 
one can't know and avoiding not wanting to know (ibid.: 309). Knowledge would be dependent on modernization risks. Many of the new dangers would not be immediately visible (e.g. radioactivity). To become visible the perceptive organs of science would be needed to produce knowledge about risks. "In this way threat situations create social dependencies of information and knowledge" (Beck 1999: 266). Only through external knowledge one could become aware of the threats one is facing (e.g. that your daily cup of tea contains DDT) (Beck 1999). Those who are affected of risks lose a significant proportion of control over knowledge and information, they are dependent on the knowledge of others, but thereby also on the non-knowledge and mistakes of experts (ibid.). Beck argues that there is no scientific monopoly of knowledge about risks because science and technology would themselves produce a great deal of risks (ibid.). Risk society would demand a reorganization of power and responsibility towards a participatory democracy that includes public risk awareness and consciousness (ibid.). Indeed the emergence of the KBS as a high risk society has brought about the formation of a certain degree of consciousness about the risks immanent in the KBS. This awareness manifests itself in new social movements that have a democratic potential. But apart from political considerations, the fact that modern science produces non-knowledge in the form of culminating modernization risks shows also that science needs conscience in order to achieve practical truth. That modern science contributes to global social problems doesn't mean that we need no science and no technology, but that we need a critical science.

The concept of practical truth implies a critical dimension of science. Robert Merton (1973) has pointed out that organized scepticism is a central aspect of science. Some scientists argues that science in modern society has the status of a religion because its knowledge would not be questioned by society (Weingart 2003: 9), or because it just like religion produces myths in society, causes order and consensus, and promises salvation (Schmutzer 1994: 122f, 147-152,; 2002) ${ }^{6}$. The truth claims of science are different from those of religion because they are permanently assessed and criticized, they are embedded into material reality and dynamic internal cultures of conflict. Science is based on the permanent critical assessment of reality and already existing theoretical works. Criticism is a fundamental aspect of science, it is a driving engine of the self-organization of science and democratic society. Due to the fact that science produces certain modernization risks, its knowledge is no longer accepted as absolute truth by society, but critically questioned.

Aspects of a critical science include:

- Recognition of the embeddedness of knowledge into social relationships as a whole, the totality of the human being and its world is explained in relationship to societal being. Society is recognized as a totality that influences all knowledge.

- Formulation of categories that question that which is, search for change and the better, concrete phenomena of society are categorized

\footnotetext{
6 "For his days Durkheim argues that the ancient gods are dying away without new ones having been born. This observation is by now about a century old. Yet, he maintained too, that scientific thought is nothing more than a more perfect version of religious thought. Sprung from religion, science tends to occupy the position of religion in society and it will take possession of every one of the intellectual and cognitive functions of religion. One of the two main functions of religion, offering a cosmology, will be lost to science. But the second one, i.e. motivating action by cults and belief, will be maintained by religion. Life has to be guided by motivations not provided by scientific insights. But guiding motivations for action and making individuals sacrifice and renounce in various ways, is exactly what the ideology of technological progress amounts to, as we have argued above. The concept of progress offers motivations, creates and propagates novel ideas of individual salvation and thus oversteps the border drawn between a scientific cosmology explaining the universe and a creed motivating for action“"(Schmutzer 2002).
} 
- Explanation of the possibilities of changing social relationships and of paths of possible historical development, analysis of the changes of society and hence of the conditions for social change, identification of possibilities for human intervention, conceptual identification of possible practices.

- Dominating categories that are frequently assumed as self-evident are challenged and put into question. Existing categories and societal facticity are not assumed as being given naturally, but are seen as historical and changeable. Ideological aspects of theory are analyzed.

- Concern for the happiness of human beings. Orientation on the advancement of human existence and the happiness of all human beings

- Knowledge production based on the insights that happiness, self-determination, and freedom can only be achieved by changing the material relationships of being, that human beings should be liberated from all forms of exploitation, oppression, and slavery, and that society should be organized intelligently, i.e. as an association of free human beings that is based on sustainable relationships between human beings and society/nature and makes use of sustainably designed technologies.

- Science, technology, and society should contribute to the development of all the faculties of human beings.

- Phantasy is necessary in order not to consider that which is as ultimate goal, to go beyond facticity, and to anticipate possible futures.

- The human being is a rational being that is in need of happiness, self-determination, and freedom. The human being is the highest being for itself. In a society that is coined by asymmetrical power relationships and heteronomy, human beings and society are alienated from their essence. Science should be oriented on humane relationships.

The processes analyzed in section 3 constitute the synchronous self-organization of science. Science can reproduce itself by the permanent mutual productive connection of scientific actors and scientific structures that produces new theoretical knowledge and truth claims. This permanent self-reproduction is a contradictory and conflicting process that from time to time results in phases of instability and crisis where more fundamentally new order emerges. Such forms of transition will now be analyzed as self-organization processes.

\section{Diachronic Scientific Self-Organization: Order from Noise in Science}

The synchronous mechanism of self-organization described above can be called the selfreproductive form of self-organization. Self-reproductive systems organize themselves by permanently producing and reproducing their components and their unity. This is a dynamic, creative process, the system permanently creates itself and produces new emergent qualities. But there is also another type of self-organization, the diachronic one that can be described as order from noise or order through fluctuation (Von Foerster 1960, Nicolis/Prigogine 1989, Prigogine 1980). Phases of self-reproduction at certain moments are followed by phases of instability where certain ordered patterns of the system break down, fluctuations and chaos and intensify themselves. From this disorder new order emerges that is partly unpredictable. A number of authors has tried to conceive sociological models in analogy to the principle of order from noise (Laszlo 1996, Jantsch 1975, 1979, Wallerstein 1991, 1998; Mueller-Benedict 2001, Fuchs 2003b). Applying this general philosophical principle to society means that the overall self-reproduction of society is not a smooth, permanently stabile process, it is in constant flux and from time to time enters phases of crisis. These are periods of instabilities where the further development of the overall social system is not determined. 
From time to time, a social systems enters crisis and phases of instability due to social contradictions. The self-reproduction of a social system takes place permanently. Selfreproduction results at a certain bifurcation point results in order from noise, it is predetermined that each social system or certain aspects of it will at a certain point of time collapse, but the exact point of time, the exact causes, and the exact outcome (i.e. the new form of order) are largely undetermined. The old structures condition a field of possibilities, a certain number of possible alternatives, but it is not determined which alternative path will be realized. Diachronic social self-organization is shaped by a dialectic of chance and necessity.

The idea of order from noise can also be applied to science as a self-organizing social system in order to describe the dynamic evolution of this system. Self-reproduction of science means that the mutual productive process between scientific actors and scientific structures results in the permanent emergence of new theoretical knowledge. In each development phase of science and a scientific discipline, there are certain dominant theories, norms, rules, values, and guidelines that dominate the system and are largely influential. These patterns are considered as being successful ways of solving scientific and societal problems. However, these dominant structural patterns of science have a historical character, science and society change dynamically, and it eventually will be the case that scientific and societal problems develop differently than scientific theories. If a large gap between scientific theory and the problems posed for science by itself and by society emerges, the dominant structural patterns are increasingly questioned. This can have scientific or wider societal causes, or a combination of both. Hence if an antagonism between scientific theories and scientific problems emerges this means that theory is no longer able to adapt to the reality of science and society and becomes outdated. In such a phase of instability, scientists look for different problem solving mechanisms, fundamentally new structural patterns of science emerge. That there is fundamental novelty means that existing modes of scientific production and action, theories, values, positions, institutions, rules, norms, and values are considered as outdated and substituted by other structural patterns. Novelty here concerns the relationship of a new and an old development phase of science, but it can be the case that that which is considered as new indeed is a synthesis of much older theories and ways of thinking formulated in a new terminology. But in comparison to the prior development phase, a fundamental change of dominant patterns can be asserted. Such a scientific phase of bifurcation results in fundamental scientific change, i.e. the patterns of behaviour, thinking, communication as well as the structures of science change to a certain extent that is much larger than in the normal, self-reproductive phase of scientific development. Variation is a permanent phenomenon of scientific evolution, but in phases of instability where the self-organization of science shifts from self-reproduction to order from noise the degree of variation and development by chance is much larger. But it is not fully left to chance how the new development phase will look like, scientific and social development and the problems that they pose determine a field of possible developments, struggles and power conflicts within science select which path of possible development will be realized in such a phase.

Science self-organizes in such a way that phases of relative stability are followed by phases of fundamental innovations. The latter constitute discontinuous breaks that are characterised by rapid change and fluctuations from which new scientific order emerges. During such scientific bifurcation points a new scientific paradigm emerges. Such a paradigm refers to the "entire constellation of beliefs, values, techniques, and so on shared by the members of a given community" (Kuhn 1962: 175). Some important aspects of a scientific paradigm that Thomas Kuhn (1962) has pointed out and that are still important and topical for an evolutionary theory of science are: 
- Researchers whose work is based on shared paradigms are committed to the same rules and standards for scientific practice.

- A paradigm is connected to the dominance of a certain theory or a set of homologous theories.

- Certain phases of development of a scientific system or discipline are based on the dominance of a paradigm, such a phase is called "normal science", indicating the dominance of certain scientific achievements.

- In a phase of normal science no major novelties are produced, but knowledge grows cumulatively based on the dominant paradigm and on the creation of discoveries (novelties of fact).

- Normal science brings with it a strong network of commitment to certain concepts, theories, instruments, and methods for those who share the paradigm.

- The emergence of a new paradigm is preceded by scientific crisis, i.e. a phase of professional insecurity, failure of normal science in solving certain problems, and difficulties in the paradigm-nature-fit.

- A paradigm shifts takes place during a scientific revolution, the successive transition from one paradigm to another via revolution is the usual developmental pattern of mature science.

- There are battles about the acceptance of possible new paradigms, paradigm shifts involve conflicts between competing schools of thought.

- A paradigm shift is a discontinuous process of reconstruction.

- Scientific revolutions can be of different size, and hence effect subsystems of science that are of different scope. Certain revolutions effect certain communities, but don't necessarily extend to other ones.

- The main reason why a new paradigm establishes itself is because it is more successful or believed to be more successful than its competitors and its predecessors in solving certain problems.

- The emergence of a new paradigm is both creative and destructive.

- Paradigm shifts are accompanied by changes in world view.

- A paradigm shift doesn't mean pure novelty, there is a certain degree of continuation.

The evolution of science is a discontinuous process ${ }^{7}$ that results in a new development stage. Such paradigm shifts can be both found in particular scientific disciplines as well as in science as a general system. Paradigm shifts can either be limited to certain scientific disciplines or effect overall science. For Kuhn paradigm shifts are due to intersubjective changes of beliefs, science is seen as a quite autonomous system detached from society, there are not much connections in his theory between science and society, the causality between social changes and scientific changes is not taken into account, the logic of scientific development is considered as purely internalistic, subjectivistic and individualistic; scientific innovations are seen as individual chance discoveries.

Kuhn doesn't take into account the dialectic of subjectivity and objectivity that applies to the development of science as a self-organizing system. Paradigm shifts are not merely left to chance (i.e. they are not the pure result of free human activity), but they are to a certain extent conditioned by the development of science and society and the problems these development

\footnotetext{
7 "The transition from a paradigm in crisis to a new one from which a new tradition of normal science can emerge is far from a cumulative process, one achieved by an articulation or extension of the old paradigm. Rather it is a reconstruction of the field from new fundamentals, a reconstruction that changes some of the field's most elementary theoretical generalizations as well as many of its paradigm methods and application" (Kuhn 1962: 84).
} 
processes pose. Paradigm shifts are on the scientific level frequently connected to conflicts between opposing models, approaches and theories, and on the societal level to the development of social antagonisms. Science is not a closed system, it is mutually coupled to all other subsystems of society, hence social changes can result in scientific change just like important scientific changes frequently result in wider social changes. Apart from these subjectivistic shortcomings one must acknowledge that Thomas Kuhn has made important contributions to the foundations of a dynamic, evolutionary concept of science.

Important paradigm shifts in the history of science have e.g. been the shift from Ptolemaic astronomy to Copernican astronomy, the change from the geocentric to the heliocentric world view, Galileo's work that questioned Aristotelian physics, Kepler's theory of planetary motion, Newton's works, the $17^{\text {th }}$ century scientific revolution, Einstein's theories of special and general relativity that questioned ideas of absolute motion, absolute space, and absolute time, or the change from Newtonian mechanics to quantum mechanics to.

I want to give two example that show the connection of social and scientific change.

During the last decades an increasing body of scientific literature on topics of selforganization has emerged that taken together represents a huge shift of focus in science. This is a shift from mechanistic determinism to complexity studies, evolutionary and process thinking. There are shifts:

- from structures and states to processes and functions

- from self-correcting to self-organising systems

- from hierarchical steering to participation

- from conditions of equilibrium to dynamic balances of non equilibrium

- from single trajectories to bundles of trajectories

- from linear causality to circular causality

- from predictability to relative chance

- from order and stability to instability, chaos and dynamics

- from certainty and determination to a larger degree of risk, ambiguity and uncertainty

- from reductionism to emergentism

- from being to becoming

- from decomposable units to connection and networks

This paradigm shift has both scientific (subjective) and wider societal (objective) causes. With the mechanistic and deterministic world view scientists were during the last decades no longer able to explain spontaneity in nature and society, hence they had to look for alternative modes of explanation. The crisis of the development model of modern society known as Fordism that has been followed by the emergence of the Postfordist development model has resulted in the emergence of new social qualities that represent societal shifts (cf. e.g. Fuchs 2003a):

- from mass production to flexible specialization

- from Taylorism to flexible accumulation

- from assembly lines to computerized production/automation

- from hierarchical organizations to decentralized network organizations

- from the welfare state to neo-liberal regulation

- from standardization to individualization

- from external coercive disciplines to internal control

- from collectivism to individualism

- from industrialism to informationalism

- from the national to the global

- from the space of places to the space of flows 
These wider societal shifts from Fordism to Postfordism effect all subsystems of society and hence have also transformed the structures of science and the tasks that it has to face. Taken together with subjective (i.e. system-specific) changes of the scientific system these objective conditions have caused the paradigm shift.

Another example that shows that scientific changes are connected to social changes is the transformation of science in the Third Reich. The Nazis systematically eliminated scientists that didn't share their ideology and installed a scientific paradigm that was based on concepts like race, volksgemeinschaft, nation, leadership, family, authority, nature, homeland, lebensraum, species. This paradigm was opposed to categories like class, class struggle, society, individual. It was holistic, irrational, and biologistic in character, and based on a massive ideologization of science.

Cumulative theories of scientific development have argued that there is a historical increase of scientific knowledge, scientific progress, and the truthfulness of science. It is a simple fact that the amount of scientific knowledge must historically increase, and thus far it has indeed increased exponentially. The permanent growth of scientific knowledge can be verified statistically (cf. fig. 5). "On a worldwide basis, scientific articles increased by 14 percent between 1986 and 1999, an average of 1 percent growth per year" ${ }^{\prime 8}$ (National Science Board 2002). Another interesting indicator of the growth of scientific knowledge is the number of citations in patents to scientific and technical literature (cf. fig. 6). In the USA the "number of patent citations to articles appearing in any of the world's scientific and technical literature increased rapidly since the mid-1980s. They stood at about 22,000 in 1985 , reached almost 123,000 in 1995, then more than doubled to reach more than 310,000 in 1998 " (ibid.). In the period 1985-2000 period 1985-2000 "the average number of citations per U.S. patent increased more than fivefold" (ibid.).

\footnotetext{
${ }^{8}$ The decisive indicator used in this study is the volume of articles published in the world's key science and technology journals.
} 
Figure 5-32.

Growth trends in scientific and technical publications by region: $1986-99$

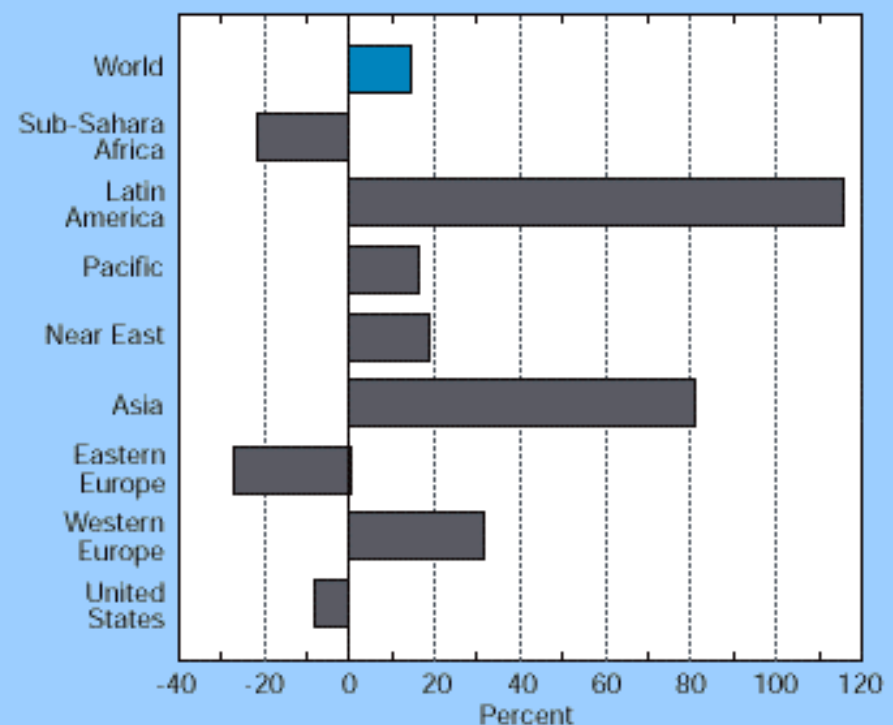

See appendix table 5-41. Science \& Engineering indicators - 2002

Figure 5-33.

Output of scientific and technical papers for the U.S. and OECD: $1986-99$

1986 index $=100$

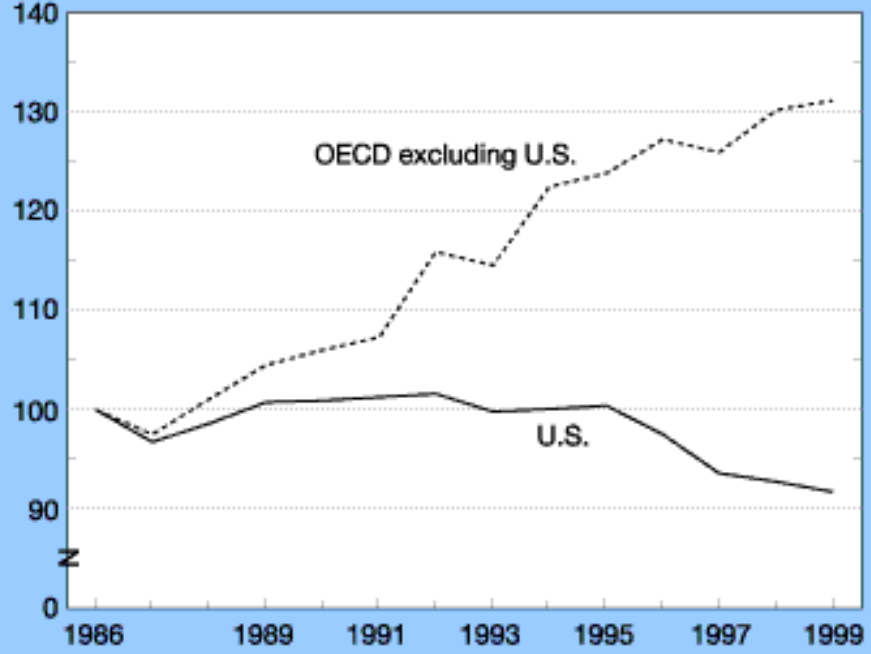

OECD = Organisation for Economic Co-operation and Development NOTE: OECD count includes only high income (as defined by the World Bank) members.

See appendix table 5-41. Science \& Engineering Indicators - 2002

Fig. 5: The growth of scientific papers, 1996-1999, Source: National Science Board (2002), Fig. 5-32, 5-33 
Figure 5-45.

Number of citations in U.S. patents to scientific and technical articles: 1985-2000

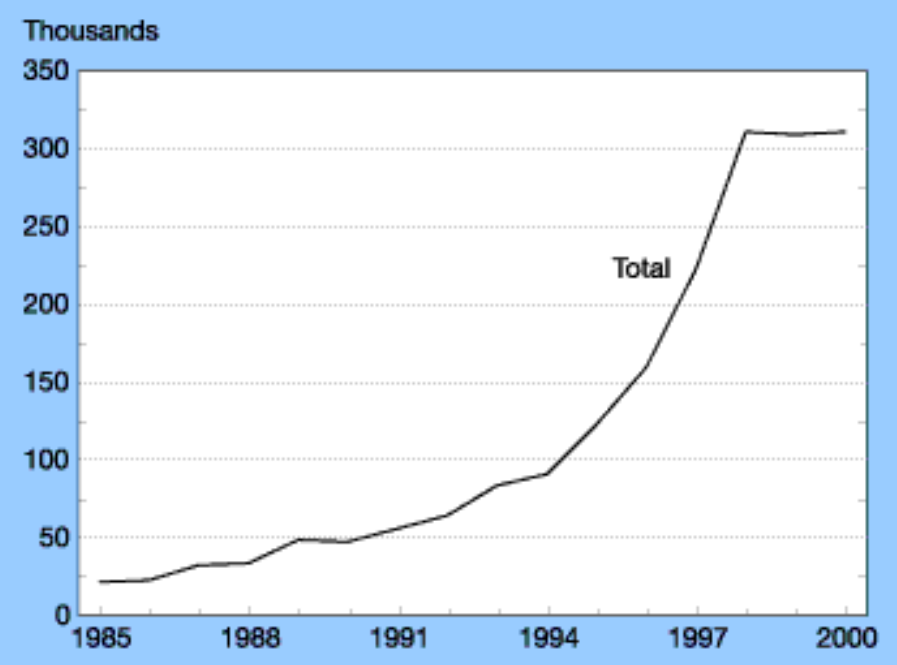

NOTES: Citations include all references to scientific articles. Citation counts are on the basis of a twelve-year period with a three-year lag; for example 2000 citations are references of U.S. patents issued in 2000 to articles that were published 1986-97. Changed U.S. Patent \& Trademark Office procedures, greater ease of locating scientific articles, and greater incentive to cite them may have contributed to some of these increases.

SOURCES: U.S. Department of Commerce, Patent and Trademark Office; CHI Research, Inc., Science Indicators and Patent Citations databases; and National Science Foundation, Division of Science Resources Statistics.

Sclence \& Engineering Indicators - 2002

Fig. 6: Growth of the number of citations in US patents, 1985-2000, Source: National Science Board, Fig. 5-45

The rapid growth of scientific knowledge is mainly due to the fact that societal development has been accompanied by the evolution of the mass media that has allowed a massive increase of the speed and efficiency of information transmission, processing, and storage. The printing press and the computer are the main symbols of these developments. These media have also changed science in such a way that the speed, extensity, intensity, and efficiency of scientific production and communication has historically increased and these growth rates have themselves been steadily growing. The growth of scientific knowledge is a simple fact, but this doesn't automatically mean that there is more progress, endeavour, or truth in science today than in former times. If the capacity for solving societal problems is an indicator of the progress of science, we must indeed say that modernization has on the one hand brought scientific progress in the sense of technologies that allow a massive reduction of the overall societal workload, an increase of the speed of production, the globalization of social relationships, etc., but this progress has on the other hand been accompanied by high risks if one thinks e.g. of the techniques of vaporization in the Third Reich, the development of the atom bomb, science's contribution to the Cold War and the arm's race, the risks caused by nuclear energy, war technology, etc. Hence science contributes to the transition towards a high risk society and it is highly questionable that there is an automatic evolutionary scientific progress. There is no scientific progress independent from social progress. Scientific progress pretty much depends on wider societal implications and consequences of science, hence scientific progress requires overall social progress and can only be adequately realized if science is approached with humanistic goals by scientists and society. 
Scientific truths can hardly be measured and change dynamically, new theories replace old theories, hence there is also the phenomenon of the devaluation and outdating of scientific theories ${ }^{9}$. It is mainly empirical scientific knowledge that devalues quickly, whereas theoretical knowledge can also be revived if it has already been forgotten. Not only truth, but also error is an aspect of scientific development. Certain old theories are no longer considered as true because they have no longer much scientific and social relevance, they still exist in libraries, but are hardly active part of actual scientific research and the knowledge the latter produces. The phenomenon of outdated theories is an argument against the historical progressive accumulation of scientific truths. In certain cases older theories are heavily revitalized and integrated into new theories and terminologies because they seem to be appropriate in certain situations. In each phase of development of science and scientific disciplines, different traditions and lines of thinking exist concurrently, complete each other, or compete against each other. Hence we have to speak of a plurality of actualized theories. New theories always are built upon old theories, they synthesize various theories, concepts, traditions, etc. and have new, emergent properties. Nonetheless it can be said that there are dominant theories and traditions in each development phase and that there are also theories that are hardly used any longer or have simply been forgotten, ignored, or overlooked.

Scientific knowledge is only cumulative in the sense that it has a historical character and that the amount of knowledge increases historically. But this is only a quantitative aspect of science, more important are qualitative similarities and differences between various approaches, traditions, and lines of thought. Hence an evolutionary view of scientific development focuses on how the increase of the quantity of research again and again turns into new qualitative aspects of knowledge and on the fact that science evolves discontinuously and involves both truths and errors. These sublations of scientific knowledge can involve the revival of old theories, the creation of completely new theories, the synthesis of various theories, etc. I.e. scientific knowledge has numerous paths and possibilities of development. In a phase of scientific development that is dominated by a certain scientific paradigm, theoretical knowledge develops and increases continuously. But once science enters a crisis, i.e. a phase of instability and bifurcation, a certain amount of scientific knowledge devalues in the sense that it is no longer much useful in solving scientific and societal problems. There is also much scientific knowledge objectified in the form of research articles that has no substantial value for science because it is never read by anyone due to the fact that there is a massive overload of theoretical knowledge in all research fields that can't be efficiently dealt with by single researchers or research teams. Discontinuous paradigm shifts mean also the breakdown of cumulative growth. Measuring certain aspects of science such as its manpower, the degree of qualification of scientists, the number of journals, publications, and references, etc. as is done in scientometrics is a necessary tool for describing the development of science, but it can't and shouldn't substitute for qualitative theoretical development models of science that can take into account qualities that a purely quantitative and cumulative analysis of science can't consider.

A dynamic and evolutionary view of scientific development is opposed to simple growth models of science. Thomas Kuhn has made important contributions to the establishment of such thinking. Another important thinker in this respect has been Karl Mannheim who has pointed out the relationship of dialectical thinking and evolutionary thinking within his

\footnotetext{
${ }^{9}$ „Wissenschaftliche Theorien werden nicht kumuliert wie bloße Fakten, sondern im Theorienwechsel umgearbeitet zu neuen Theorien, die die alten entwerten und überflüssig machen“ (Oeser 1976b: 127). Translation: "Scientific theories are not accumulated like pure facts, but in a paradigm shift transformed into new theories that devalue the old ones and make the latter superfluous“".
} 
sociology of knowledge. Mannheim (1952) argued that all thinking of a social group is determined by its existence. Both knowledge and existence would be evolving. Mannheim's evolutionary theory of knowledge was opposed to static and unhistorical conceptions of knowledge that have been put forward by idealistic thinkers like Max Scheler who consider knowledge as endless, timeless spiritual entity that forms the substance of social existence. For Scheler (1926) the sociology of knowledge was part of cultural sociology that would research timeless characteristics of man. In the Platonic tradition Scheler argues that ideas are pre-existent to their realisation, they would be changeless and timeless. He calls this realm of fixed knowledge the "absolute sphere". Changing material reality would be secondary and created by the world of endless ideas. The possibilities of being would be pre-determined by mind, the real cultural factors could only make a selection from these possibilities. For Scheler the essential ultimate is something pre-existent and ideal, floating above history, he postulates a supra-temporal, unchanging system of truths.

In opposition to Scheler, Karl Mannheim proposed a more dynamical theory of knowledge that conceives knowledge as historically developing. For him knowledge does not exist metaphysically outside or above history, but is constituted historically in social processes. Knowledge would be developing in such a way that a new knowledge system incorporates older knowledge, it forms a higher level, eliminates the old system, but also preserves it. It "sublimates" the old system (Mannheim 1952: 170) and is organized around a new centre. Norbert Elias (1971) has pointed out that knowledge is subject to a long-term development process, it would have a "process-character" (Elias 1971: 361) and a "character of a structured flux" (ibid.: 364). Thinkers like Mannheim and Elias have anticipated conceiving knowledge as dynamic process that has been made fully possible by the emergence of the theories of selforganization that are a suitable methodological tools for describing complex, dynamic, interrelated phenomena. Hence we see us standing more in the dialectical and evolutionary tradition of Mannheim than in the static and idealistic tradition of Scheler.

Mannheim has clearly pointed out that dialectical principles such as sublation (i.e.

"Aufhebung" in the sense of elimination, preservation, and uplifting), negation of the negation, contradiction, and turn from quantity into quality can be applied to the development process of knowledge. Mannheim's (and hence also Hegel's and Marx's) philosophical concept of evolution is still important for conceiving science as a dynamic, self-organizing information system because scientific knowledge develops in such a way that new theoretical knowledge systems incorporate older knowledge, forms a higher level of development, eliminates old knowledge and knowledge systems, although it preserves certain aspects of it.

\section{Conclusion}

I have argued in this paper that self-organization theory puts forward a dialectical logic and hence the basic problems of a theory of science that concern epistemology, structure, causality, and dynamics should when conceiving science as a self-organizing system be solved dialectically. I have tried to make a contribution to bridging strict oppositions between categories such as induction/deduction, actors/structures, internal/external, continuity/discontinuity. Dialectical reasoning allows to show how dual categories are opposed, but at the same time require each other. This contradiction causes development and the emergence of a higher form of identity and unity of the opposites that is itself again opposed and mutually connected to a dual pole.

I have argued that in science scientific actors and structures produce each other mutually. This process is based on human creativity that is enabled and constrained by social structures. The 
theorem of the duality of structure allows a dialectical conception of the relationship of actors/structures in since. Hence science is a system that develops as a process and permanently produces higher qualities. The permanent emergence of new qualities means that theories are permanently changed, novelty emerges on lower levels of science. I have argued that the dualism between induction and deduction can be resolved dialectically if one conceives theory as a self-referential structure that develops permanently by mutually connecting experiences and theory and considering scientific knowledge as a cyclical process of advancing from the abstract to the concrete, and returning from the concrete to the abstract. The permanent mutual connection of theory and experience and of actors and structures in science allows continuous dynamic change on a synchronous level and the growth of scientific knowledge. However, from time to time the self-reproduction of science enters phases of instability because an antagonism between scientific theory and scientific and social problems emerges. In such a phase of heavy fluctuations, crisis, and bifurcation, old dominant knowledge is sublated and devalued and a new scientific paradigm emerges as fundamental novelty in a process of order from noise. The self-reproduction of science operates both continuously and discontinuously, conceiving science as a self-organizing system allows us to show that science is self-reproducing/self-referential on a synchronous level and that this selfreproduction operates in phases of stability that are followed by phases of instability where fundamental novelty emerges. Such an approach allows to conceive the relationship of continuity and discontinuity dialectically. Self-organizing systems are relatively autonomous systems. This means that they have their own logic of development, but this logic is not fully independent of exernal factors. Self-organizing systems are open systems, they exchange matter, energy, and information with their environment. In the case of social systems this means that such systems are closely connected to and influenced by social systems in their environment. Conceiving science as self-organizing allows to explain the development of this system as a complex interplay between genuinely scientific factors and external factors that stem from the economy, polity, and culture.

\section{References:}

Beck, Ulrich (1994a) The Reinvention of Politics. Towards a Theory of Reflexive Modernization. In: Beck, Ulrich/Giddens, Anthony/Lash, Scott (1994) Reflexive Modernization. Cambridge. Polity Press. pp. 1-55.

Beck, Ulrich (1994b) Self-Dissolution and Self-Endangerment of Industrial Society: What Does it Mean? In: Beck, Ulrich/Giddens, Anthony/Lash, Scott (1994) Reflexive Modernization. Cambridge. Polity Press. pp. 174183.

Beck, Ulrich (1996) Wissen oder Nicht-Wissen? Zwei Perspektiven „,reflexiver Modernisierung “. In: Beck, Ulrich/Giddens, Anthony/Lash, Scott (1994) Reflexive Modernisierung. Frankfurt/Main. Suhrkamp. pp. 289-315.

Beck, Ulrich (1999) Modern Society as a Risk Society. In: Meja, Volker/Stehr, Nico (Eds.) (1999) The Sociology of Knowledge. 2 Volumes. Cheltenham/Northampton. Edgar Elgar. Vol. 2, pp. 262-277.

Bloch, Ernst (1963) Tübinger Einleitung in die Philosophie. Frankfurt/Main. Suhrkamp.

Bloch, Ernst (1975) Experimentum Mundi. Frage, Kategorien des Herausbringens, Praxis. Frankfurt/Main. Suhrkamp.

Bourdieu, Pierre (1998) Vom Gebrauch der Wissenschaft. Für eine klinische Soziologie des wissenschaftlichen Feldes. Konstanz. Universitäts-Verlag.

Elias, Norbert (1971) Sociology of Knowledge. New Perspectives. In: Sociology, 5(2+3), pp.149-168+355-370.

Fuchs, Christian (2002a) Concepts of Social Self-Organisation. INTAS-Project "Human Strategies in Complexity“-Research Report (Online: http://www.self-organization.org). 69 pages. Vienna. Vienna University of Technology.

Fuchs, Christian (2002b) Social Information and Self-Organisation. In: Robert Trappl (Hrsg.) (2002) Cybernetics and Systems 2002. Proceedings of the 16th European Meeting on Cybernetics and Systems Research. Vienna. Austrian Society for Cybernetic Studies. Vol. 1. pp. 225-230. 
Fuchs, Christian (2003a) Globalization and Self-Organization in the Knowledge-Based Society. In: tripleC (http://triplec.uti.at), Vol. 1, No. 2, pp. 105-169.

Fuchs, Christian (2003b) The Self-Organization of Modern Society. In: Studies in Political Economy, Vol. 25 (2003) (forthcoming, accepted paper, PrEprint: Social Science Research Network eLibrary:

http://ssrn.com/abstract=385220).

Fuchs, Christian (2003c) Structuration Theory and Self-Organization. In: Systemic Practice and Action Research, Vol. 16 (2003), No. 4. pp. 133-167.

Fuchs, Christian (2003d) The Self-Organisation of Politics, Power and the Nation State. "Human Strategies in Complexity" Research Paper. In: Social Science Research Network eLibrary: http://ssrn.com/abstract=385222

Fuchs, Christian (2003e) The Internet as a Self-Organizing Socio-Technological System. "Human Strategies in Complexity" Research Paper. In: Social Science Research Network eLibrary: http://ssrn.com/abstract=458680

Fuchs, Christian (2003f) Some Implications of Pierre Bourdieu's Works for a Theory of Social SelfOrganisation. In: European Journal of Social Theory, Vol. 6, No. 4., pp. 387-409.

Fuchs, Christian (2003g) Co-operation and Social Self-Organisation. In: tripleC (Cognition, Communication, Co-operation) (http://triplec.uti.at), Vol. 1 (2003), No. 1. pp. 1-52.

Fuchs, Christian (2003h) Dialectical Philosophy and Self-Organisation. In: Arshinov, Vladimir/Fuchs, Christian (Eds.) (2003) Causality, Emergence, Self-Organisation. Moscow. NIA-Priroda.

Fuchs, Christian (2004) The Political System as a Self-Organizing Information System. In: Trappl, Robert (Ed.) (2004) Cybernetics and Systems 2004. Vienna. Austrian Society for Cybernetic Studies (forthcoming).

Fuchs, Christian/Hofkirchner, Wolfgang (2003a) Studienbuch Informatik und Gesellschaft. Norderstedt. Libri.

Fuchs, Christian/Hofkirchner, Wolfgang (2003b) The Architecture of the Information Society. In: Wilby, Jennifer/Allen, Janet K. (Eds.) (2003) Proceedings of the $47^{\text {th }}$ Annual Conference of the International Society for the Systems Sciences (ISSS) “Agoras of the Global Village”, July 7-11, 2003, Iraklion, Crete. CD-ROM: ISBN 0-9740735-1-2.

Fuchs, Christian/Hofkirchner, Wolfgang (2004) Knowledge and Self-Organization. In: Kybernetes, Special Issue on Heinz von Foerster (forthcoming).

Fuchs, Christian/Hofkirchner, Wolfgang/Klauninger, Bert (2002) The Dialectic of Bottom-Up- and Top-DownEmergence in Social Systems. Talk at the Conference "Problems of Individual Emergence", Amsterdam, April, $16^{\text {th }}-20^{\text {th }} 2001$. In: Proceedings of the Conference Problems of Individual Emergence (forthcoming)

Fuchs, Christian/Schlemm, Annette (2004) The Self-Organisation of Society. In: Natur \& Ökonomie, Vol. 1, No. 1 (forthcoming).

Giddens, Anthony (1984) The Constitution of Society. Berkeley. University of California Press.

Hofkirchner, Wolfgang (1998) Emergence and the Logic of Explanation. An Argument for the Unity of Science. In: Acta Polytechnica Scandinavica, Mathematics, Computing and Management in Engineering Series 91, 23-30.

Hofkirchner, Wolfgang (Ed.) (1999a) The Quest for a Unified Theory of Information. Proceedings of the Second International Conference on the Foundations of Information Science. Amsterdam. Gordon and Breach.

Hofkirchner, Wolfgang (1999b) Cognitive Sciences in the Perspective of a Unified Theory of Information. In: Allen, J. K., Hall, M. L. W., Wilby, J. (Eds.) Proceedings of the 43rd Annual Conference of ISSS (The International Society for the Systems Sciences), ISBN 09664183-2-8 (CD-ROM)

Hofkirchner, Wolfgang (2002) Projekt Eine Welt - Kognition, Kommunikation, Kooperation. Münster. LIT.

Hörz, Herbert (1988) Wissenschaftsentwicklung als Typenwandel. In: Kröber, Günter (Ed.) (1988) Wissenschaft - Das Problem ihrer Entwicklung. Band 2: Komplementäre Studien zur marxistisch-leninistischen

Wissenschaftstheorie. Berlin. Akademie. pp. 299-314.

Jantsch, Erich (1975) Design for Evolution. New York. George Braziller.

Jantsch, Erich (1979/1992) Die Selbstorganisation des Universums. Vom Urknall zum menschlichen Geist. München/Wien. Hanser.

Kröber, Günter (1988) Wissenschaftsentwicklung als irreversibler gesellschaftlicher Prozess. In: Kröber, Günter (Ed.) (1988) Wissenschaft - Das Problem ihrer Entwicklung. Band 2: Komplementäre Studien zur marxistischleninistischen Wissenschaftstheorie. Berlin. Akademie. pp. 155-186

Krohn, Wolfgang/Küppers, Günter (1989) Die Selbstorganisation der Wissenschaft. Frankfurt/Main. Suhrkamp. 
Krohn, Wolfgang/Küppers, Günter (1990) Science as a Self-Organizing System. In: Krohn/Küppers/Nowotny (1990), pp. 208-222.

Krohn, Wolfgang/Küppers, Günter/Nowotny, Helga (Eds.) (1990) Selforganization. Portrait of a Scientific Revolution. Dordrecht. Kluwer.

Kuhn, Thomas (1962) The Structure of Scientific Revolutions. Chicago. University of Chicago Press.

Laszlo, Ervin (1996) Evolution: the general theory. Cresskill, New Jersey. Hampton.

Latour, Bruno (1987) Science in Action. Cambridge, Mass. Harvard University Press.

Lévy, Pierre (1998) Becoming Virtual. Reality in the Digital Age. New York/London. Plenum.

Luhmann, Niklas (1990) Die Wissenschaft der Gesellschaft. Frankfurt/Main. Suhrkamp.

Mannheim, Karl (1952) Essays on the Sociology of Knowledge. Routledge. London.

Marcuse, Herbert (1963) One-Dimensional Man. Studies in the Ideology of Advanced Industrial Society.

London. Routledge.

Marx, Karl (1857) Einleitung zu den Grundrissen der Kritik der Politischen Ökonomie. In: MEW, Vol. 42.

Berlin. Dietz, pp. 19-45.

Marx, Karl (1857/58) Grundrisse der Kritik der politischen Ökonomie. Berlin. Dietz. MEW, Vol. 42.

Marx, Karl (1894) Das Kapital. Kritik der politischen Ökonomie. Band 3: Der Gesamtprozess der kapitalistischen Produktion. Berlin. Dietz. MEW, Vol. 25.

Merton, Robert K. (1968) The Matthew Effect In Science. In: Science, 159(3810), pp. 56-63.

Merton, Robert K. (1973) Wissenschaft und demokratische Sozialstruktur. In: Weingart, Peter (Ed.) (1973)

Wissenschaftssoziologie I. Wissenschaftliche Entwicklung als sozialer Prozess. Frankfurt/Main Athenäum. pp. 45-59.

Merton, Robert K. (1996) On Social Structure and Science. Chicago. Chicago University Press.

Mueller-Benedict, Volker (2001) Selbstorganisation in sozialen Systemen. Erkennung, Modelle und Beispiele nichtlinearer Dynamik. Opladen. Leske + Budrich.

National Science Board (2002) Science and Engineering Indicators - 2002. Arlington, VA. National Science Foundation (NSB-02-1).

Nicolis, Gregoire/Prigogine, Ilya (1989) Exploring Complexity. New York. Freeman.

Oeser, Erhard (1976a) Erkenntnis als Informationsprozess, Vol. 1: Wissenschaftstheorie und empirische Wissenschaftsforschung. Vienna/Munich. Oldenbourg.

Oeser, Erhard (1976b) Erkenntnis als Informationsprozess, Vol. 2: Erkenntnis als Informationsprozess. Vienna/Munich. Oldenbourg.

Oeser, Erhard (1976c) Erkenntnis als Informationsprozess, Vol. 3: Struktur und Dynamik erfahrungswissenschaftlicher Systeme. Vienna/Munich. Oldenbourg.

Oeser, Erhard (1988) Das Abenteuer der kollektiven Vernunft. Evolution und Involution der Wissenschaft. Berlin/Hamburg. Parey.

Price, Derek De Solla (1963) Little Science, Big Science. New York. Columbia University Press.

Prigogine, Ilya (1980) From Being to Becoming. New York. Freeman

Scheler, Max (1990) The Sociology of Knowledge. Formal and Material Problems. In: Meja, Volker/Stehr, Nico (Eds.) (1990) Knowledge and Politics. The Sociology of Knowledge Dispute. London/New York. Routledge. pp. 17-36.

Schmutzer, Manfred E.A. (1994) Ingenium und Individuum. Eine sozialwissenschaftliche Theorie von Wissenschaft und Technik. Wien/New York. Springer.

Schmutzer, Manfred E.A. (2002) The Immaculate Conception of Progress. Is Religion an Obstacle to Progress? Ms. http://info.tuwien.ac.at/itg/texte/cs3.html

Stehr, Nico (1994) Knowledge Societies. The Transformation of Labour, Property and Knowledge in Contemporary Society. London. Sage.

Stichweh, Rudolf (1990) Self-Organization and Autopoiesis in the Development of Modern Science. In: Krohn/Küppers/Nowotny (1990), pp. 195-207. 
Von Foerster, Heinz (1960) On Self-Organizing Systems and Their Environments. In: Von Foerster, Heinz (1995) Cybernetics of Cybernetics. Minneapolis. Future Systems. pp. 220-230.

Wallerstein, Immanuel (1991) Unthinking Social Science. New York. Polity Press.

Wallerstein, Immanuel (1998) Utopistics: or, Historical Choices for the Twenty-First Century. New Yor:k. New Press.

Weingart, Peter (2003) Wissenschaftssoziologie. Bielefeld. transcript.

Willke, Helmut (2002) Dystopia. Frankfurt/Main. Suhrkamp. 